\title{
Modulation of $\mathrm{H}_{2} \mathrm{~S}$ Metabolism by Statins: A New Aspect of Cardiovascular Pharmacology
}

\author{
Jerzy Bełtowski and Anna Jamroz-Wiśniewska
}

\begin{abstract}
Significance: Statins (3-hydroxy-3-methylglutarylcoenzyme A reductase inhibitors) are commonly used in the treatment of cardiovascular diseases. Statins reduce plasma low-density lipoproteins, inhibit inflammatory reaction, improve endothelial function, ameliorate oxidative stress, and reduce platelet activity. Consequently, statins markedly decrease the risk of acute cardiovascular events. $\mathrm{H}_{2} \mathrm{~S}$ is synthesized in all layers of the vascular wall, including the endothelium, smooth muscle cells, and perivascular adipose tissue (PVAT). Recent Advances: Recent studies demonstrate that PVAT-derived $\mathrm{H}_{2} \mathrm{~S}$ decreases vascular tone by activating $\mathrm{K}_{\mathrm{ATP}}$ and/or KCNQ potassium channels in smooth muscle cells. Lipophilic atorvastatin, but not hydrophilic pravastatin, increases net $\mathrm{H}_{2} \mathrm{~S}$ production in PVAT by inhibiting its mitochondrial oxidation, and augments the anticontractile effect of PVAT. Inhibition of $\mathrm{H}_{2} \mathrm{~S}$ metabolism results from atorvastatin-induced decrease in coenzyme $\mathrm{Q}$, which is a cofactor of $\mathrm{H}_{2} \mathrm{~S}$ oxidation by sulfide:quinone oxidoreductase. In contrast to $\mathrm{H}_{2} \mathrm{~S}$, statins do not impair mitochondrial oxidation of organic substrates. Critical Issues: Taking into account antiatherosclerotic and antiinflammatory effect of $\mathrm{H}_{2} \mathrm{~S}$, the gas may mediate some of the beneficial effects of statins on the cardiovascular system. In addition, specific statins differ in their ability to enhance $\mathrm{H}_{2} \mathrm{~S}$ signaling. Future Directions: Since both statins and $\mathrm{H}_{2} \mathrm{~S}$ reduce ischemia-reperfusion injury, the possible effect of statins on $\mathrm{H}_{2} \mathrm{~S}$ oxidation in other tissues such as the heart and the kidney needs to be examined. Inhibition of $\mathrm{H}_{2} \mathrm{~S}$ metabolism may be a new therapeutic strategy to improve $\mathrm{H}_{2} \mathrm{~S}$ signaling, especially in the mitochondrial compartment. Antioxid. Redox Signal. 17, 81-94.
\end{abstract}

\section{Statins: Mechanism of Action and Clinical Application}

S TATINS ARE COMPETITIVE INHIBITORS of 3-hydroxy-3methylglutarylcoenzyme A (HMG-CoA) reductase-a rate-limiting enzyme in cholesterol synthesis-which converts HMG-CoA to mevalonate (22) (Fig. 1). The first statin, mevastatin, was discovered in the 1970s by the Japanese microbiologist, Akira Endo, in the fermentation broth of Penicillium citrinium during the search of potential new suppressors of lipid metabolism. The first clinically used statin, lovastatin, discovered in Aspergillus terreus in 1978, was approved by Food and Drug Administration for the treatment of hypercholesterolemia in 1987. By inhibiting HMG-CoA reductase in the liver, statins up-regulate the expression of the low-density lipoprotein receptor (LDL-R), thus accelerating the metabolism of LDLs. Statin-induced intracellular cholesterol depletion results in the activation of sterol regulatory element-binding protein-2 (SREBP-2) - the sterol-sensitive transcription factor that up-regulates the expression of LDL-R in maintaining intracellular cholesterol balance. SREBP-2 also up-regulates the expression of HMG-CoA reductase, partially counteracting the hypocholesterolemic effect of statins.
Although this effect is negligible in humans, in some mammalian species such as the rat, it is very marked and overcomes statin-induced inhibition of the enzyme; consequently, statins have little or no effect on plasma cholesterol concentration in the rat. Currently used statins may reduce plasma LDL cholesterol by $30 \%-40 \%$ in patients with primary (genetically-determined) and secondary hypercholesterolemia. Since elevated LDL cholesterol is a major risk factor of atherosclerosis, statins effectively reduce the incidence of acute cardiovascular events in both primary and secondary prevention of ischemic heart disease and cerebrovascular diseases $(51,52)$. Therefore, statins are among the most widely used medications in cardiovascular disorders. Apart from reducing LDL cholesterol, statins exert other beneficial effects on plasma lipid profile such as a decrease in triglyceride concentration, lowering of atherogenic small dense LDL, and an increase in the antiatherogenic high-density lipoproteins (74).

However, effects of statins extend far beyond their impact on cholesterol synthesis. Indeed, mevalonate, the product of statin-inhibited reaction, is also the precursor of many other biologically active molecules (Fig. 1). The best known of them, farnesyl- and geranylgeranyl-pyrophosphates, are attached to

Departments of ${ }^{1}$ Pathophysiology and ${ }^{2}$ Neurology, Medical University, Lublin, Poland. 


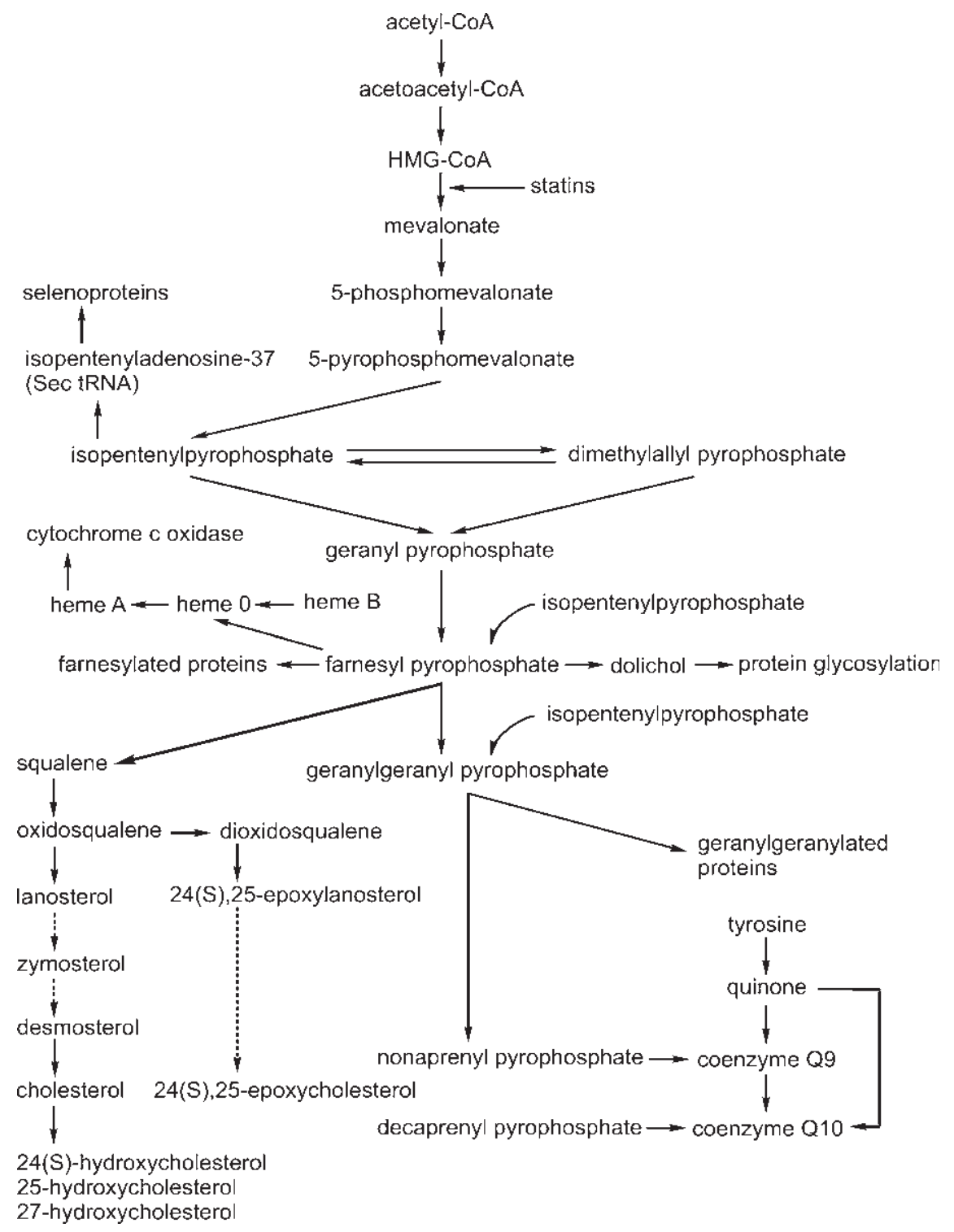

FIG. 1. Mevalonate cascade. Statins inhibit the rate-limiting enzyme of the mevalonate cascade, 3-hydroxy-3methylglutaryl coenzyme A (HMG$\mathrm{CoA})$ reductase, which converts HMG-CoA to mevalonate. Mevalonate is the precursor of many biologically important compounds (see text for details). Broken lines represent the abbreviated multi-step reactions. various proteins in the process referred to as protein isoprenylation, which is catalyzed by protein farnesyl- and geranylgeranyltransferases, respectively. The most important isoprenylated proteins are those belonging to the small GTPbinding (small G protein) family. Among them, Ras proteins, which are farnesylated, are involved in signal transduction by growth factor receptors and activate mitogen-activated protein kinase cascade. In contrast, Rho proteins, which are geranylgeranylated, regulate vesicle transport, assembly, and activation of phagocytic and nonphagocytic NADPH oxidases, cytoskeleton reorganization, and activation of Rho-dependent kinase, which regulates smooth muscle cell contractility and growth. Inhibition of protein farnesylation and/or geranylgeranylation is responsible for lipid-independent or "pleiotropic" effects of statins such as amelioration of oxidative stress, improvement of endothelial nitric oxide (NO) production, inhibition of adhesion protein expression, and leukocyte migration, decreased synthesis of proinflammatory cyto- and chemokines, inhibition of cell hypertrophy/proliferation (including antihypertrophic effect on vascular smooth muscle cells crucial for growth of atherosclerotic plaque), and beneficial modification of coagulation/fibrinolysis balance (6). Pleiotropic effects contribute significantly to antiatherosclerotic properties of statins, which are evident not only in patients with hypercholesterolemia but also in those with normal cholesterol levels $(51,55)$. Lipid-independent effects of statins are responsible for stabilization of atherosclerotic plaque and mediate rapid improvement of prognosis in statin-treated patients with acute coronary syndromes or cerebral stroke, which is evident before any effect on the lipid profile appears. In addition, due to their pleiotropic effects, statins are beneficial in animal models of and in humans with other pathologies such as ischemia-reperfusion injury, heart failure, osteoporosis, Alzheimer disease, multiple sclerosis, and rheumatoid arthritis (6).

In contrast to cholesterol and isoprenyl pyrophosphates, inhibition of other mevalonate derivatives is rather involved in adverse effects of statins. Coenzyme Q (CoQ) consists of a benzoate ring originating from tyrosine and polyisoprene side chain synthesized from farnesyl pyrophosphate. The predominant form (about 95\%) of CoQ in humans is $\mathrm{CoQ}_{10}$ containing 10 isoprene units in the side chain, whereas in the 
rat, $\mathrm{CoQ}_{9}$ predominates. CoQ exists in either reduced (ubiquinol) or oxidized (ubiquinone) form; transition between them allows it to function as an electron carrier in the mitochondrial respiratory chain. CoQ accepts electrons from mitochondrial complex I (NADH:ubiquinone oxidoreductase) and complex II (succinate:quinone oxidoreductase) and transfers them to complex III (ubiquinone:cytochrome c reductase). In addition, ubuquinol is an important lipid-soluble antioxidant in plasma membranes and plasma lipoproteins. CoQ is the only endogenous lipid-soluble antioxidant in mammals and the only one that on oxidation may be regenerated to its active reduced form by animal enzymes. Many studies have demonstrated that statins decrease plasma and tissue CoQ concentration in experimental animals and humans.

Other important mevalonate derivatives that may be inhibited by statins are oxysterols-endogenous agonists of liver $X$ receptors (LXRs). LXR are ligand-activated transcription factors that stimulate the expression of genes involved in the regulation of cholesterol export from cells, its reverse transport from peripheral tissues to the liver and biliary excretion. LXR are activated by (1) some intermediates of cholesterol synthesis, that is, desmosterol and zymosterol, (2) the product of a "shunt pathway" of cholesterol synthesis, 24(S), 25-epoxycholesterol (24,25-EC), (3) oxygenated cholesterol derivatives synthesized from cholesterol by cholesterol hydroxylases: 24(S)-hydroxy-, 25-hydroxy, and 27-hydroxycholesterol (Fig. 1). Several studies have demonstrated that statins decrease plasma and tissue concentrations of at least some oxysterols, in particular, 24,25-EC (5).

In addition, farnesylpyrophosphate is a substrate for dolichol synthesis. Dolichols are polyisoprenoid alcohols consisting of 16-21 isoprene subunits and are essential carriers of oligosaccharides for enzymatic protein glycosylation-an important post-translational modification that determines protein trafficking and function. Until now, statins have been documented to suppress insulin receptor and insulin-like growth factor 1 (IGF-1) receptor glycosylation, resulting in reduced insulin- and IGF-1 stimulated glucose uptake in cultured adipocytes (60), and to inhibit glycosylation of erythropoietin receptor in cultured erythroblastoma cells (19).

Isopentenyl pyrophosphate (Fig. 1) is also attached to adenosine-37 of selenocysteine-tRNA by tRNA isopentenyltransferase. This modification is essential for decoding UGA as a selenocysteine rather that a stop codon, which is crucial for selenoprotein synthesis. It has been demonstrated that lovastatin inhibits selenocysteine-tRNA synthesis and reduces selenoprotein content in cultured Xenopus oocytes (69). Recently, Kromer and Mossmann (29) have demonstrated that atorvastatin, cerivastatin, and lovastatin inhibit de novo synthesis of two selenoproteins, glutathione peroxidase 1 and 4, in cultured hepatoma HepG2 cells, rendering these cells more sensitive to proapoptotic effect of reactive oxygen species. In contrast, statins did not change the level of the other selenoprotein, thioredoxin reductase. It has been suggested that inhibition of selenoprotein synthesis may contribute to some common (i.e., myopathy, hepatotoxicity) and rare (hypothyroidism) side effects of statins, because clinical presentation of statin-induced myopathy closely resembles that of selenium deficiency-induced myopathy, and selenocysteinecontaining enzymes, iodothyronine deiodinases, are crucial for thyroid hormone metabolism (42). However, the effect of statins on selenoprotein synthesis in vivo has not been studied so far.

Finally, it has been suggested that statins may inhibit synthesis of heme A-the specific heme molecule being a prosthetic group of cytochrome c oxidase. Heme A is synthesized from heme $\mathrm{B}$ - the most common type of heme contained, for example, in hemoglobin-in a two-step reaction. First, heme B is farnesylated to heme $\mathrm{O}$ at the $\mathrm{C} 2$ position by heme farnesyltransferase (also called Cox10; the $10^{\text {th }}$ subunit of cytochrome c oxidase), and then hydroxyl group at the $\mathrm{C} 8$ position of heme $\mathrm{O}$ is oxidized to carboxyl group by Cox15. Cytochrome c oxidase contains two heme A molecules, both are bound to the Cox1 subunit (33). Knockout of Cox10 or Cox15 genes results in cytochrome c oxidase deficiency clinically manifesting as severe myopathy, cardiomyopathy, encephalopathy, and lactic acidosis-case reports of such symptoms in statin-treated patients have been described (5). Statins could inhibit synthesis of heme A by depleting farnesylpyrophosphate; however, this possibility has not been studied so far.

Statins may be divided into two groups: hydrophilic (pravastatin and rosuvastatin) and lipophilic (simvastatin, lovastatin, fluvastatin, atorvastatin, and pitavastatin). The structure of statins currently used in clinical practice is demonstrated in Figures 2 and 3, and their solubility in Figure 4. Cerivastatin, withdrawn from the market in 2001 due to many cases of fatal rhabdomyolysis, is also lipophilic. Lovastatin is a natural fungal metabolite, simvastatin and pravastatin are synthesized from lovastatin by chemical modifications, and the remaining statins are completely synthetic compounds. Hydrophilic statins poorly permeate plasma membranes and act primarily in the liver, because they are transported to hepatocytes by organic anion transporters. Since about $50 \%$ of LDL is metabolized in the liver, hydrophilic statins effectively reduce plasma LDL cholesterol level but have less pleiotropic extrahepatic effects. In contrast, lipophilic statins easily permeate plasma membranes and are active not only in the liver but also in extrahepatic tissues. Consequently, lipophilic statins have more pleiotropic effects in peripheral tissues as well (59).

Simvastatin and lovastatin are used as HMG-CoA reductase inactive lactone prodrugs; they are converted in vivo to active open acid forms by paraoxonase 3 (PON3) — an esterase belonging to the three-member PON family. In contrast, other statins are used in active acid forms. Simvastatin, lovastatin, and atorvastatin are metabolized in the liver by cytochrome P450 (CYP) 3A4 isoform. Fluvastatin is not metabolized by CYP3A4 but by CYP2C9. Pravastatin and rosuvastatin are excreted in substantial amounts in the urine in the unchanged form, and rosuvastatin is also partially metabolized by CYP2C9. These pharmacokinetic differences determine the half-life of specific statins and their possible interactions with other CYP-metabolized medications (59).

\section{Hydrogen Sulfide: Synthesis and Function in the Vascular Wall}

Among three known enzymatic pathways of $\mathrm{H}_{2} \mathrm{~S}$ formation, catalyzed by cystathionine $\beta$-synthase (CBS), cystathionine $\gamma$-lyase (CSE), and the concerted action of cysteine aminotransferase (CAT) and 3-mercaptopyruvate sulfurtransferase (3-MST), the latter two are operative in the 


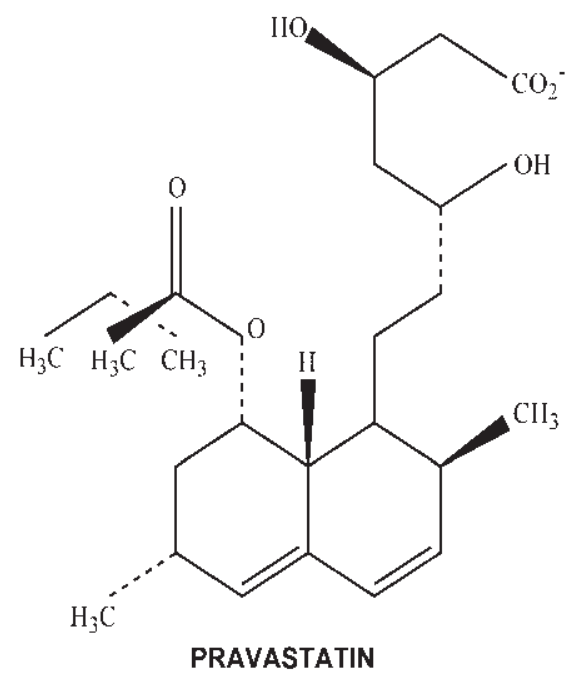<smiles>CC(C)c1nc(N(C)S(C)(=O)=O)nc(-c2ccc(F)cc2)c1/C=C/[C@H](O)C[C@@H](O)CC(=O)O</smiles>

FIG. 2. Structure of hydrophilic statins.

vascular wall (Fig. 5). Early studies suggested that CSE is expressed exclusively in vascular smooth muscle cells and is the only source of $\mathrm{H}_{2} \mathrm{~S}$ in the cardiovascular system (79). However, more recent studies indicate that the situation is much more complex. First, CSE was found in mice endothelial cells (76), and CSE-mediated $\mathrm{H}_{2} \mathrm{~S}$ production is stimulated by cholinergic agonists, making this gasotransmitter one of the possible endothelium-derived relaxing factors. In addition, both 3-MST and CAT are present in rat aortic endothelial cells, and these cells can generate $\mathrm{H}_{2} \mathrm{~S}$ from cysteine only in the presence of 2-oxoglutarate-an obligatory co-substrate of CAT-suggesting that the 3-MST dependent pathway is the only source of $\mathrm{H}_{2} \mathrm{~S}$ in endothelial cells in this species (57). However, in a recent study (23), expression of CSE in endothelial cells of rat mesenteric arteries was documented by immunohistochemical methods. In addition, endothelial denudation markedly reduced cysteine-induced vasorelaxation, indicating that endothelial CSE may be a predominant source of vascular $\mathrm{H}_{2} \mathrm{~S}$ in small resistance vessels. In bovine pulmonary artery endothelial cells, both CBS and 3-MST but not CSE

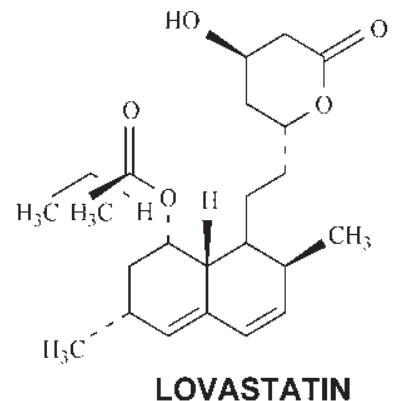

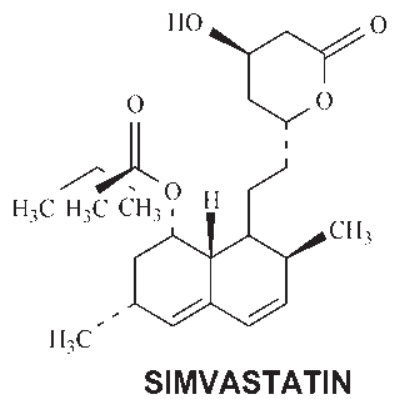<smiles>CC(C)N1c2ccccc2C(c2ccc(F)cc2)C1C=CC(O)C[C@@H](O)CC(=O)O</smiles>

FLUVASTATIN

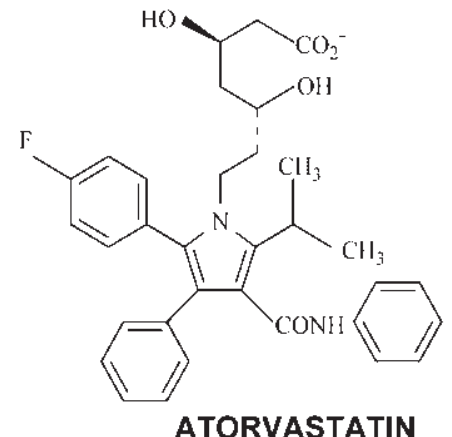

ATORVASTATIN<smiles>O=C(O)CC(O)CC=Cc1c(C2CC2)nc2ccccc2c1-c1ccc(F)cc1</smiles>

PITAVASTATIN

FIG. 3. Structure of lipophilic statins. 


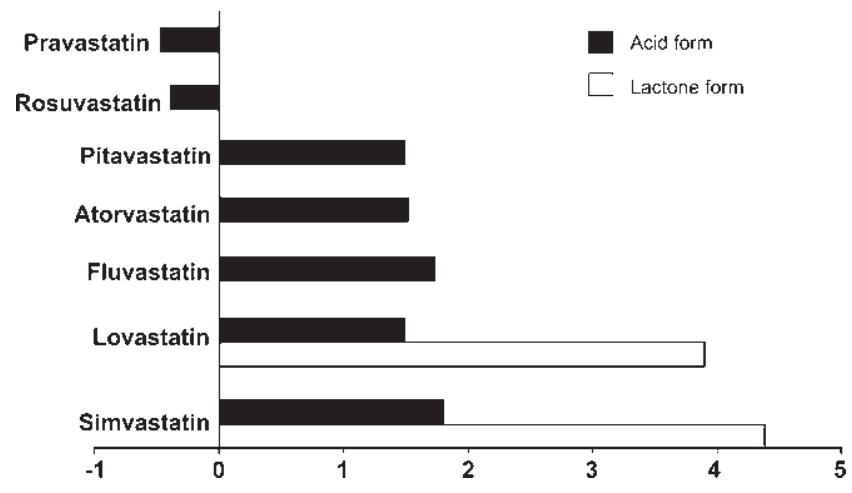

FIG. 4. Solubility of statins. Logarithms of octanol-towater distribution coefficients $(\log D)$ are presented for each individual drug according to ref. (59). Negative values are characteristic for hydrophilic and positive for lipophilic statins. For lovastatin and simvastatin, used clinically as the inactive precursor lactones, $\log \mathrm{D}$ values are presented for both lactone (white bars) and acid forms (black bars).

are expressed (47). $\mathrm{H}_{2} \mathrm{~S}$ concentration in plasma and aortic tissue is markedly reduced in CSE knockout mice, thus demonstrating that CSE is the principal source of $\mathrm{H}_{2} \mathrm{~S}$ in the cardiovascular system (76).

Although in vitro studies suggest that CSE can synthesize $\mathrm{H}_{2} \mathrm{~S}$ also from homocysteine and that the contribution of homocysteine increases in hyperhomocysteinemia (12), it is unclear whether homocysteine serves as a $\mathrm{H}_{2} \mathrm{~S}$ precursor in vivo. Recently, it has been demonstrated that concentration of free $\mathrm{H}_{2} \mathrm{~S}$ (i.e., excluding sulfane sulfur and acid-labile sulfur) in the murine aortic wall is 20-200 times higher than in many other tissues, including the brain, liver, heart, kidney, and striated muscles, thus indicating that $\mathrm{H}_{2} \mathrm{~S}$ plays an important role in vascular homeostasis (34).

The best-characterized role of $\mathrm{H}_{2} \mathrm{~S}$ in the cardiovascular system is the regulation of vascular tone. Currently available data

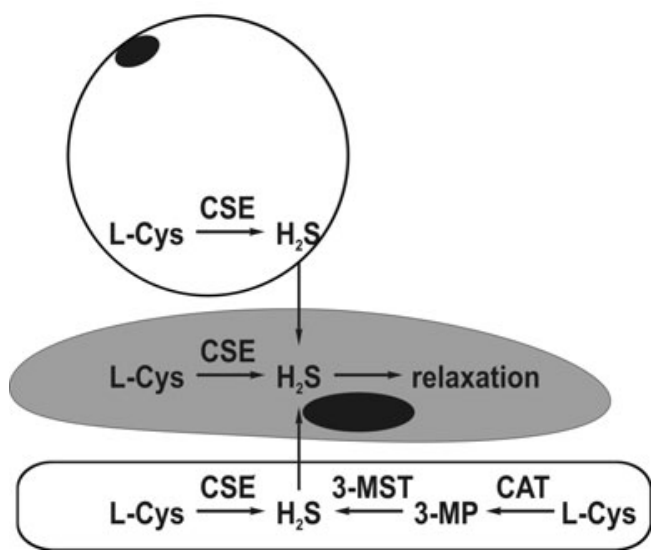

FIG. 5. Enzymatic synthesis of $\mathrm{H}_{2} \mathrm{~S}$ in the vascular wall. In both smooth muscle cells (middle) and perivascular adipocytes (top), $\mathrm{H}_{2} \mathrm{~S}$ is produced from L-cysteine (L-Cys) by cystathionine $\gamma$-lyase (CSE). In endothelial cells (bottom), $\mathrm{H}_{2} \mathrm{~S}$ may be synthesized by either CSE or cysteine aminotransferase (CAT) and 3-mercaptopyruvate sulfurtransferase (3MST) with 3-mercaptopyruvate (3-MP) as the intermediate product. allow concluding that $\mathrm{H}_{2} \mathrm{~S}$ has a complex and concentrationdependent effect of vascular tone (Fig. 6) with vasoconstriction at a lower and vasodilation at a higher concentration $(1,70)$. However, the precise mechanisms through which $\mathrm{H}_{2} \mathrm{~S}$ regulates vascular tone demonstrated in various studies depends on animal species, vascular bed, and experimental conditions (measurement of isometric or isotonic tension, agonists induced to predilate or preconstrict the vessels before studying the effect of $\mathrm{H}_{2} \mathrm{~S}$, etc.) [see ref. (4) for review]. $\mathrm{H}_{2} \mathrm{~S}$-induced vasoconstriction may results from (1) inhibition of L-arginine transport to endothelial cells by cationic aminoacid transporter, (2) attenuation of protein kinase B/Akt-induced phosphorylation of endothelial nitric oxide synthase (eNOS), (3) direct inhibition of eNOS, (4) scavenging of $\mathrm{NO}$ to form inactive nitrosothiol, (5) inhibition of adenylate cyclase and

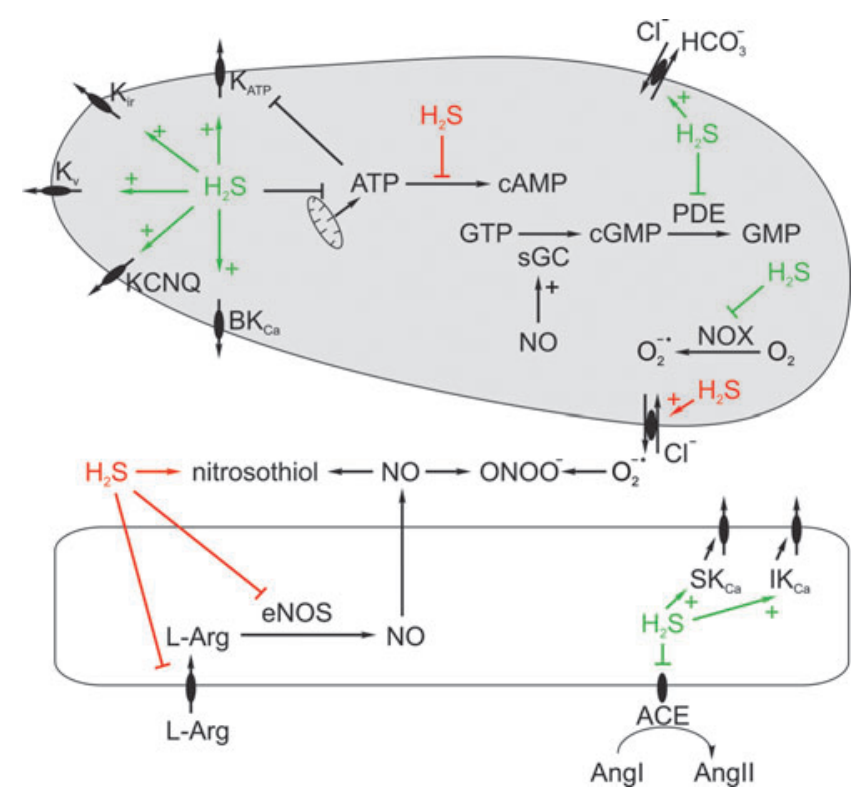

FIG. 6. Mechanisms of vascular tone regulation by $\mathrm{H}_{2} \mathrm{~S}$. $\mathrm{H}_{2} \mathrm{~S}$ may dilate blood vessels by activating different types of potassium channels, that is, ATP-inhibited ( $\left.\mathrm{K}_{\mathrm{ATP}}\right)$, inwardly rectifying (Kir), voltage-sensitive $(\mathrm{Kv}), \mathrm{KCNQ}$, and large conductance $\mathrm{Ca}^{2+}$-activated $\left(\mathrm{BK}_{\mathrm{Ca}}\right)$. By suppressing cytochrome c oxidase, $\mathrm{H}_{2} \mathrm{~S}$ may inhibit ATP synthesis leading to the de-repression of $\mathrm{K}_{\mathrm{ATP}}$ channels. Vasodilation may also be mediated by activation of $\mathrm{HCO}_{3}{ }^{-}$efflux through the $\mathrm{HCO}_{3}{ }^{-} / \mathrm{Cl}^{-}$exchanger, inhibition of cGMP-degrading phosphodiesterase (PDE), angiotensin-converting enzyme (ACE), and NADPH oxidase (NOX) - the source of nitric oxide (NO) scavenger, superoxide $\left(\mathrm{O}_{2}^{-\bullet}\right)$. Finally, by stimulating endothelial cell small- and intermediate-conductance $\mathrm{Ca}^{2+}$-activated potassium channels $\left(\mathrm{SK}_{\mathrm{Ca}}\right.$ and $\left.\mathrm{IK}_{\mathrm{Ca}}\right), \mathrm{H}_{2} \mathrm{~S}$ may trigger endothelium-dependent hyperpolarization. On the other hand, $\mathrm{H}_{2} \mathrm{~S}$ may constrict blood vessels by inhibiting adenylate cyclase, scavenging $\mathrm{NO}$ to form nitrosothiol, inhibiting L-arginine (L-Arg) transport to endothelial cells and eNOS activity, as well as by stimulating efflux of superoxide, which then binds $\mathrm{NO}$ to form peroxynitrite $\left(\mathrm{ONOO}^{-}\right)$in the extracellular space. Effects of $\mathrm{H}_{2} \mathrm{~S}$ resulting in vasodilation and vasoconstriction are shown in green and red, respectively. (To see this illustration in color the reader is referred to the web version of this article at www.liebertonline.com/ ars). sGC, soluble guanylyl cyclase; eNOS, endothelial nitric oxide synthase. 
decrease in intracellular cyclic AMP in smooth muscle cells, (6) stimulation of anion exchanger-2 (AE-2) in smooth muscle cells leading to import of $\mathrm{Cl}^{-}$ions and export of superoxide anion $\left(\mathrm{O}_{2}^{--}\right)$; the latter scavenges $\mathrm{NO}$ to form peroxynitrite (37), (7) phospholipase $\mathrm{A}_{2}$-mediated release of arachidonic acid, or its cyclooxygenase-independent metabolites by endothelial cells (14).

The main mechanism of $\mathrm{H}_{2} \mathrm{~S}$-induced vasorelaxation is direct stimulation of ATP-sensitive $\mathrm{K}^{+}$channels $\left(\mathrm{K}_{\mathrm{ATP}}\right)$ in smooth muscle cells. Indeed, vasorelaxant effect of $\mathrm{H}_{2} \mathrm{~S}$ in vitro and hypotensive effect in vivo are markedly attenuated or completely abolished by $\mathrm{K}_{\mathrm{ATP}}$ antagonist, glibenclamide (79), and $\mathrm{H}_{2} \mathrm{~S}$ increases $\mathrm{K}_{\mathrm{ATP}}$ channel's open probability in intact vascular smooth muscle cells (61). $\mathrm{H}_{2} \mathrm{~S}$ stimulates $\mathrm{K}_{\mathrm{ATP}}$ channels by sulfhydrating thiol $(-\mathrm{SH})$ to persulfide $(-\mathrm{SSH})$ groups of extracellularly localized cysteine residues within the channels itself or in the accompanying subunit, sulfonylurea receptor (24). The involvement of other types of $\mathrm{K}^{+}$ channels, that is, voltage-gated $(\mathrm{Kv}), \mathrm{KCNQ}$, inwardly rectifying (Kir) and large-conductance $\mathrm{Ca}^{2+}$-activated $\left(\mathrm{BK}_{\mathrm{Ca}}\right)$ has also been suggested by some studies $(2,10,23,54)$. Other effects of $\mathrm{H}_{2} \mathrm{~S}$ on vascular smooth muscle cells have been demonstrated, including (1) stimulation of AE-2 resulting in $\mathrm{Cl}^{-} / \mathrm{HCO}_{3}{ }^{-}$exchange and cell acidification, (2) reduced affinity of $\mathrm{AT}_{1}$ receptors for angiotensin II, (3) inhibition of ATP synthesis and vasorelaxation induced by energy depletion and/or derepression of $\mathrm{K}_{\text {ATP }}$ channels, (4) inhibition of NADPH oxidase (NOX) — the main source of NO-scavenging superoxide anion in the cardiovascular system, and (5) inhibition of cGMP and/or cAMP-hydrolyzing phosphodiesterases [reviewed in ref. (4)]. Some studies suggest that vasodilating effect of $\mathrm{H}_{2} \mathrm{~S}$ may be partially endothelium dependent and mediated by either NO (78) or endothelial smalland intermediate-conductance calcium-activated potassium channels $\left(\mathrm{SK}_{\mathrm{Ca}}\right.$ and $\left.\mathrm{IK}_{\mathrm{Ca}}\right)$; the evidence of the involvement of endothelium-derived hyperpolarizing factor $(11,14)$. In addition, $\mathrm{H}_{2} \mathrm{~S}$ suppresses renin secretion by renal juxtaglomerular apparatus (39), and decreases angiotensin-converting enzyme activity in endothelial cells (30).

Despite these controversies, there is little doubt that the principal cardiovascular effect of $\mathrm{H}_{2} \mathrm{~S}$ in vivo is vasorelaxation. Indeed, intravenously administered $\mathrm{H}_{2} \mathrm{~S}$ solution or its inorganic (NaHS) or organic (GYY4137) donors decrease blood pressure, whereas CSE inhibitor has the opposite effect (36, 79). Moreover, according to some (76), although not all (21), studies, blood pressure is significantly elevated in $\mathrm{CSE}^{-/-}$ mice. Vascular $\mathrm{CSE}-\mathrm{H}_{2} \mathrm{~S}$ pathway is suppressed in experimental models of hypertension, such as spontaneously hypertensive rat and hypertension induced by chronic eNOS blockade (4).

In addition to regulating vascular tone and blood pressure, $\mathrm{H}_{2} \mathrm{~S}$ inhibits atherogenesis by multiple mechanisms (Fig. 7). In particular, $\mathrm{H}_{2} \mathrm{~S}$ suppresses proliferation and stimulates apoptosis of vascular smooth muscle cells, decreases extracellular matrix formation in the vascular wall, and inhibits synthesis of pro-inflammatory cytokines and adhesion proteins (4, 49, 71). In addition, $\mathrm{H}_{2} \mathrm{~S}$ suppresses oxidative modification of LDLs by inhibiting reactive oxygen species (ROS)-generating enzymes, NOX and myeloperoxidase, direct scavenging of ROS, and destruction of already formed lipid hydroperoxides $(31,43,44)$. Moreover, $\mathrm{H}_{2} \mathrm{~S}$ protects endothelial cells from oxidative insults induced by various factors $(3,64,75)$. Finally,

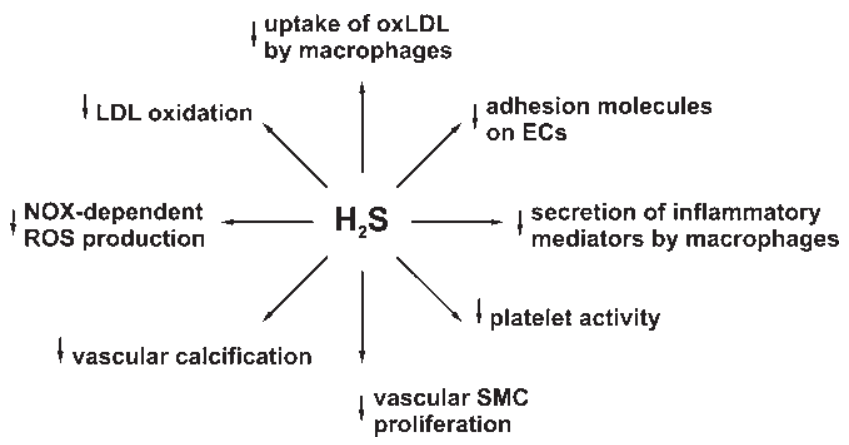

FIG. 7. The main mechanisms through which $\mathrm{H}_{2} \mathrm{~S}$ inhibits atherogenesis. ECs, endothelial cells; SMC, smooth muscle cells; NOX, NADPH oxidase; ROS, reactive oxygen species.

$\mathrm{H}_{2} \mathrm{~S}$ suppresses platelet aggregation (77), inhibits uptake of oxidatively modified lipoproteins by macrophages (80), and up-regulates anti-inflammatory and antiatherogenic heme oxygenase-carbon monoxide system in endothelial cells and macrophages (49).

Several studies indicate that $\mathrm{H}_{2} \mathrm{~S}$ inhibits atherogenesis in vivo. In particular, plasma $\mathrm{H}_{2} \mathrm{~S}$ concentration and its production in the aortic wall are significantly reduced in apolipoprotein E knockout mice-a well-established experimental model of hyperlipidemia and atherosclerosis (68). Interestingly, aortic CSE expression is up-regulated in these animals, which may be a compensatory response to $\mathrm{H}_{2} \mathrm{~S}$ deficiency. Administration of exogenous NaHS reduces, whereas CSE inhibitor, propargylglycine (PAG), aggravates atherosclerotic lesions in these animals. Similarly, $\mathrm{H}_{2} \mathrm{~S}$ deficiency was observed in rats treated with high doses of vitamin $\mathrm{D}$ and nicotine to induce vascular calcifications, and NaHS reduced vascular lesions in this model $(35,73)$. Down-regulation of CSE- $\mathrm{H}_{2} \mathrm{~S}$ pathway was also demonstrated in balloon-induced injury of rat carotid artery-a model of vascular restenosisand treatment with NaHS ameliorated neointimal hyperplasia in the injured vessel (41).

\section{$\mathrm{H}_{2} \mathrm{~S}$ in Perivascular Adipose Tissue as a Vasodilator}

Most large and small arteries are surrounded by adipose tissue referred to as perivascular adipose tissue (PVAT). PVAT is a part of visceral adipose tissue and consists of both white and brown adipocytes. Brown adipocytes contain large amounts of mitochondria and are highly metabolically active, they also express uncoupling protein-1 at the high level and, thus, may oxidize fatty acids or other substrates in the uncoupled manner, that is, energy is dissipated as heat rather than stored in ATP (50). Although neglected in most studies concerning the regulation of vascular tone, PVAT is an integral part of the vascular wall. It was first demonstrated in 1991 that rat aortic rings with PVAT were less responsive to constricting effect of norepinephrine than aortic rings without PVAT; however, the effect was initially attributed to norepinephrine uptake by adipocytes or sympathetic endings localized in PVAT. In 2002, Löhn et al. (38) demonstrated that vasoconstricting effects of angiotensin II, serotonin and phenylephrine (an $\alpha_{1}$-adrenergic agonist) were also smaller in aortic rings with PVAT than in those without PVAT, and suggested that periadventitial adipose tissue secretes humoral 
relaxing factor which they named adipose tissue-derived relaxing factor (ADRF). It was demonstrated that ADRF activity is not accounted for by NO, adenosine, and cyclooxygenaseor cytochrome P450-dependent arachidonate derivatives. Furthermore, vasodilating effect of ADRF was abolished by high, depolarizing extracellular $\mathrm{K}^{+}$concentrations, suggesting the involvement of potassium channels. In addition, the effect of ADRF was at least partially attenuated by $\mathrm{K}_{\mathrm{ATP}}$ channel blocker, glibenclamide (38). Apart from rat aortic rings, subsequent studies demonstrated the anticontractile effect of periadventitial fat on peripheral arteries that play a more significant role in the regulation of systemic vascular resistance than large conduit vessels (65).

In 2009, Fang et al. (17) demonstrated that incubation of homogenates of rat periaortic adipose tissue (PAAT) with cysteine in the presence of pyridoxal 5'-phosphate resulted in $\mathrm{H}_{2} \mathrm{~S}$ formation. $\mathrm{H}_{2} \mathrm{~S}$ production in PAAT itself was comparable to that in the aortic wall with removed PAAT, and was inhibited by $65 \%-75 \%$ with CSE inhibitors, PAG or $\beta$-cyano-Lalanine. These data suggest that CSE is the main source of $\mathrm{H}_{2} \mathrm{~S}$ in PVAT. In addition, the expression of CSE in PAAT was demonstrated by Western blotting, and CSE protein was found in adipocytes by immunohistochemistry (17). $\mathrm{H}_{2} \mathrm{~S}$ concentration measured by sulfur-sensitive electrode was twofold higher in the incubation medium of PAAT + than of PAAT - rat aortic rings. It should be noted that 3-MST dependent pathway of $\mathrm{H}_{2} \mathrm{~S}$ production could not be detected in that study, because 2-oxoglutarate was not added to the incubation medium. Thus, it cannot be excluded that 3-MST dependent pathway is also operative in the adipose tissue.

Demonstration of $\mathrm{H}_{2} \mathrm{~S}$ synthesis in PAAT led to the hypothesis that it can mediate ADRF activity. Indeed, increase in aortic tension induced by serotonin or phenylephrine was lower in PAAT + than in PAAT - rat aortic rings, and in PAAT - rings, this anticontractile effect could be mimicked by exogenous $\mathrm{H}_{2} \mathrm{~S}$. The mixture of L-cysteine and pyridoxal 5'phosphate augmented, whereas CSE inhibitors abolished the anticontractile effect of PAAT, while having no effect on vascular tone of PAAT - rings. The anticontractile effect of PAAT was not affected by endothelial removal or NO synthase inhibitor, L-NAME, but was abolished by glibenclamide. Moreover, transfer of incubation/culture medium from PAAT + aortic rings or isolated periadventitial adipocytes to PAAT - rings reduced constricting effect of phenylephrine, serotonin or angiotensin II, and this effect could not be observed if donor PAAT was preincubated with CSE inhibitors before medium collection. Taken together, these results indicate that $\mathrm{H}_{2} \mathrm{~S}$ produced in PAAT by CSE reduces vasoconstriction by activating $\mathrm{K}_{\mathrm{ATP}}$ channels in vascular smooth muscle cells (17).

Subsequently, Schleifenbaum et al. (54) have demonstrated that the presence of PVAT also impairs serotonin-induced contractility of rat mesenteric artery. In contrast to aortic rings, the anticontractile effect of PVAT on the mesenteric artery was not affected by $\mathrm{K}_{\mathrm{ATP}}$ channel antagonist, but was reduced by nonspecific inhibitor of voltage-sensitive $\mathrm{K}^{+}$ channels, 4-aminopyridine, as well as by the specific antagonist of Kv7.x (KCNQ) channels, XE991. In contrast, XE991 had no effect on serotonin-induced contraction of mesenteric artery rings with removed PVAT. Similarly to aorta, anticontractile effect of PVAT on mesenteric artery was abolished by CSE inhibitors. In addition, NaHS relaxed mesenteric ar- tery rings without PVAT, and this effect was inhibited by XE991. Taken together, these data indicate that PVAT-derived $\mathrm{H}_{2} \mathrm{~S}$ reduces vascular tone also in small resistance arteries; however, in contrast to aorta, its effect is not mediated by $\mathrm{K}_{\mathrm{ATP}}$ but rather by $\mathrm{KCNQ}$ channels. It was also demonstrated that KCNQ channel activators such as retigabine or VRX0621688 induced more prominent vasorelaxation of PVAT- rings or PVAT + rings treated with CSE inhibitor in comparison to PVAT + rings not treated with CSE inhibitors. These results indicate that KCNQ channel-mediated vasorelaxing mechanism is "saturated" by PVAT-derived $\mathrm{H}_{2} \mathrm{~S}$ under physiological conditions. Thus, KCNQ channel activators might be especially useful vasodilators when $\mathrm{CSE}-\mathrm{H}_{2} \mathrm{~S}$ pathway in PVAT is impaired.

Given the role of PVAT-derived $\mathrm{H}_{2} \mathrm{~S}$ in the regulation of vascular tone, it is interesting if and how the $\mathrm{CSE}-\mathrm{H}_{2} \mathrm{~S}$ pathway is modulated by hemodynamic factors. Fang et al. (17) have demonstrated that phenylephrine, serotonin, and angiotensin II increased $\mathrm{H}_{2} \mathrm{~S}$ production from L-cysteine in isolated PAAT. In contrast, these vasoconstrictors reduced $\mathrm{H}_{2} \mathrm{~S}$ production in aortic rings without PAAT. Since stimulation of $\mathrm{H}_{2} \mathrm{~S}$ release was observed in isolated PAAT without adjacent aortic wall, it could not result from vasoconstriction itself but rather from the direct effect of these mediators on adipose cells.

In experimental hypertension induced in the rat by constriction of the abdominal aorta, $\mathrm{H}_{2} \mathrm{~S}$ synthesis and CSE expression in the aortic wall without PAAT was unchanged in comparison to control normotensive animals; however, $\mathrm{H}_{2} \mathrm{~S}$ production and CSE expression in PAAT increased by $70 \%$ and $130 \%$, respectively. Plasma $\mathrm{H}_{2} \mathrm{~S}$ level was also slightly higher in hypertensive animals. Thus, the CSE- $\mathrm{H}_{2} \mathrm{~S}$ system in PAAT could be a back-up vasodilatory mechanism, which is up-regulated in response to both acute effect of vasoconstrictors and chronic hypertension.

\section{Effect of Statins on $\mathrm{H}_{2} \mathrm{~S}$ in PVAT}

Taking into account antihypertensive and antiatherogenic properties of $\mathrm{H}_{2} \mathrm{~S}$, elevating, its level could be a potential novel therapeutic strategy for cardiovascular diseases. However, $\mathrm{H}_{2} \mathrm{~S}$ donors currently used in research are not suitable for pharmacotherapy. Inorganic salts, such as $\mathrm{NaHS}$ or $\mathrm{Na}_{2} \mathrm{~S}$, are converted to $\mathrm{H}_{2} \mathrm{~S}$ in aqueous solutions, but this process results in rapid formation of large supraphysiological amounts of $\mathrm{H}_{2} \mathrm{~S}$. In addition, these salts easily undergo spontaneous oxidation in solutions, and the fraction of undissociated membrane-permeable $\mathrm{H}_{2} \mathrm{~S}$ is highly $\mathrm{pH}$ dependent. Consequently, it is very difficult to precisely control tissue concentration especially in the in vivo setting. Several $\mathrm{H}_{2} \mathrm{~S}$-releasing derivatives of anti-inflammatory and other currently used drugs such as diclofenac, naproxen, aspirin, mesalamine, valproic acid, and sildenafil have been synthesized. However, these derivatives retain the activity of a parent compound and, in addition, dithiolethione moiety used as a $\mathrm{H}_{2} \mathrm{~S}$-releasing group has some $\mathrm{H}_{2} \mathrm{~S}$-independent effects. Organic $\mathrm{H}_{2} \mathrm{~S}$-releasing compounds without other activities such as GYY4137 are available (36). However, these agents are now at the early stage of experimental research and their clinical application is at best a matter of future.

Nevertheless, $\mathrm{H}_{2} \mathrm{~S}$ may also be modulated by currently used cardiovascular medications but, until now, very little is 
known about it. Therefore, we examined the effect of statinsone of the most commonly used drugs in cardiovascular medicine- on $\mathrm{H}_{2} \mathrm{~S}$ formation in the vascular wall (72). We performed this study in healthy normolipidemic rats. Although statins do not reduce plasma cholesterol in the rat, this species is a good model to study cholesterol-independent pleiotropic effects of statins. In addition, in the rat, statins decrease plasma triglycerides, and this effect correlates with the extent of LDL-cholesterol reduction in humans (28). We used two representative statins: hydrophilic pravastatin and lipophilic atorvastatin, and administered them for 3 weeks at doses of 20 and $40 \mathrm{mg} / \mathrm{kg} /$ day, respectively; these doses of prava- and atorvastatin exert comparable effects on the lipid profile (reduction of triglycerides by about 30\%-35\%). Then, we examined $\mathrm{H}_{2} \mathrm{~S}$ formation catalyzed by aortic media and PAAT homogenates under optimal conditions (saturating Lcysteine and pyridoxal 5'-phosphate concentrations). Before homogenization, endothelium was removed to avoid possible interactions between $\mathrm{H}_{2} \mathrm{~S}$ and $\mathrm{NO}$ of endothelial origin. Consistently with results obtained by Fang et al. (17), we observed that aortic media and PAAT homogenates were able to synthesize $\mathrm{H}_{2} \mathrm{~S}$ from L-cysteine and this synthesis was almost completely abolished by CSE inhibitor. We found that only atorvastatin, but not pravastatin, increased $\mathrm{H}_{2} \mathrm{~S}$ production in PAAT, whereas neither statin had any effect in the aortic media. Both statins increased $\mathrm{H}_{2} \mathrm{~S}$ production in the liver. Thus, we identified new pleiotropic lipid-independent effect of statins in the vascular wall (72).

To examine whether the effect of atorvastatin has any implications for vascular tone, we studied phenylephrineinduced contractility of endothelium-denuded aortic rings. We found that although contraction induced by high $\mathrm{KCl}$ concentration was independent of the presence of PAAT, and was not modified by statin treatment, phenylephrine-induced contractility was attenuated in rings containing PAAT in comparison to those with removed PAAT (Fig. 8). This anticontractile effect of PAAT was abolished by either PAG or glibenclamide that had no significant effect on the contractility of PAAT - rings. In addition, PAAT + rings isolated from atorvastatin but not from pravastatin-treated animals exhibited less contractility in response to phenylephrine. In contrast, atorvastatin treatment had no effect on the contractility of PAAT - rings (Fig. 8). Preincubation of PAAT + aortic rings isolated from atorvastatin-treated rats with either PAG or glibenclamide increased phenylephrine-induced contractility and eliminated the difference between atorvastatintreated and control rats. Taken together, these results indicate that PAAT-derived $\mathrm{H}_{2} \mathrm{~S}$ decreases vascular tone by activating $\mathrm{K}_{\mathrm{ATP}}$ channels, and atorvastatin treatment augments this effect (72).

\section{Mechanism of Statin-Induced Increase in $\mathrm{H}_{2} \mathrm{~S}$}

Recent studies indicate that steady-state tissue $\mathrm{H}_{2} \mathrm{~S}$ level is very low, because the gasotransmitter is rapidly oxidized in mitochondria. Hydrogen sulfide was known to be oxidized by some bacteria; however, its metabolism by eukaryotic mitochondria is a relatively novel finding (8). $\mathrm{H}_{2} \mathrm{~S}$ is the first and the only currently known inorganic substrate for eukaryotic mitochondria that can provide energy for ATP synthesis. $\mathrm{H}_{2} \mathrm{~S}$ is first oxidized to the level of elemental sulfur (sulfane sulfur of protein-SSH groups) by sulfide:quinone
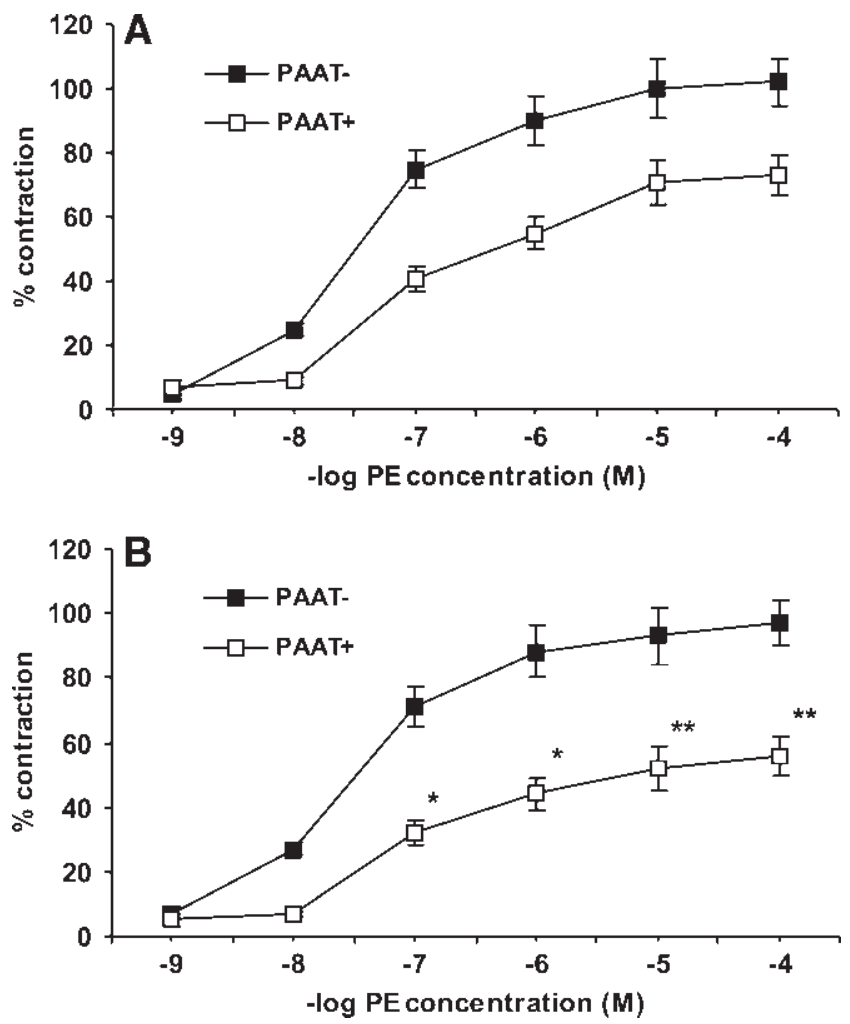

FIG. 8. Contraction of isolated rat aortic rings with intact (PAAT+, white squares) or removed (PAAT-, black squares) periaortic adipose tissue in response to phenylephrine. On the horizontal axis is presented negative logarithm of phenylephrine (PE) concentration and on the vertical axis percent of contraction induced by $\mathrm{PE}$ in comparison to maximal contraction induced by $60 \mathrm{mM} \mathrm{KCl}$. Aortic rings were isolated from control rats (top panel, $\mathbf{A}$ ) and rats treated with atorvastatin for 3 weeks (bottom panel, B). Intact PAAT reduced contractility in both groups. There was no difference in PE-induced contractility of PAAT - rings between groups; however, contractility of PAAT + rings was smaller in atorvastatin-treated rats. ${ }^{*} p<0.05,{ }^{* *} p<0.001$ in comparison to contractility of control PAAT + rings induced by the same PE concentration [reproduced with permission from ref. (72)]. PAAT, periaortic adipose tissue.

oxidoreductase (SQR). The enzyme transfers electrons from $\mathrm{H}_{2} \mathrm{~S}$ to ubiquinone where they enter mitochondrial respiratory chain. Further steps of $\mathrm{H}_{2} \mathrm{~S}$ oxidation are catalyzed by sulfur dioxygenase (ETHE1, enzyme deficient in inherited ethylmalonic encephalopathy) that oxidizes elemental sulfur to sulfite $\left(\mathrm{SO}_{3}{ }^{2-}\right)$, and sulfite oxidase which oxidizes sulfite to sulfate $\left(\mathrm{SO}_{4}{ }^{2-}\right)$. The involvement of additional enzymes (thiosulfate sulfurtransferase and thiosulfate reductase) and thiosulfate $\left(\mathrm{S}_{2} \mathrm{O}_{3}{ }^{2-}\right)$ as the intermediate was suggested but is not definitely proved (20).

In our initial experiments just described, $\mathrm{H}_{2} \mathrm{~S}$ formation was measured in postnuclear tissue supernatants that contain both cytosol (where CSE is localized) and mitochondria. Thus, the net $\mathrm{H}_{2} \mathrm{~S}$ production is measured under these conditions and was the difference between gas synthesis and metabolism. To elucidate which of these processes is affected by statins, we measured $\mathrm{H}_{2} \mathrm{~S}$ production separately also in postmitochondrial supernatants. We found that $\mathrm{H}_{2} \mathrm{~S}$ formation 
in postmitochondrial supernatants of both PAAT and liver was higher than in postnuclear supernatants. In addition, $\mathrm{H}_{2} \mathrm{~S}$ production from L-cysteine in postmitochondrial supernatant was not affected by statins. Statins had no effect on CSE activity toward its primary substrate, L-cystathionine, measured in PAAT and liver (72). The difference in $\mathrm{H}_{2} \mathrm{~S}$ formation between postmitochondrial and postnuclear supernatants is a putative mitochondrial $\mathrm{H}_{2} \mathrm{~S}$ oxidation. Neither statin had any effect on $\mathrm{H}_{2} \mathrm{~S}$ oxidation calculated in this manner in the aortic media, whereas atorvastatin, but not pravastatin, reduced it in PAAT. The calculated $\mathrm{H}_{2} \mathrm{~S}$ oxidation in the liver was higher in both prava- and atorvastatin-treated rats than in control animals (72).

Subsequently, we repeated these experiments in the incubation medium which was deoxygenated by bubbling with the $\mathrm{N}_{2}$ gas. $\mathrm{H}_{2} \mathrm{~S}$ formation in postmitochondrial supernatants measured in deoxygenated buffer tended to be slightly higher $(10 \%-15 \%)$ than in normally oxygenated buffer; this difference presumably represents spontaneous $\mathrm{H}_{2} \mathrm{~S}$ oxidation. In contrast, $\mathrm{H}_{2} \mathrm{~S}$ formation in postnuclear supernatants measured under anoxic conditions was much higher than measured under normoxic conditions. The difference between $\mathrm{H}_{2} \mathrm{~S}$ formation between postmitochondrial and postnuclear supernatants measured under anoxic conditions was close to 0 and was not affected by statins either in PAAT or in the liver (72). These results are consistent with previous findings that mitochondrial $\mathrm{H}_{2} \mathrm{~S}$ oxidation is compromised under hypoxic conditions (32).

To further confirm that the difference in $\mathrm{H}_{2} \mathrm{~S}$ formation between postmitochondrial and postnuclear supernatants indeed represents mitochondrial $\mathrm{H}_{2} \mathrm{~S}$ oxidation, we measured this difference in livers obtained from control rats in the presence of inhibitors of mitochondrial complex I (rotenone), complex III (myxothiazole), or complex IV (potassium cyanide). We found that both myxothiazole and $\mathrm{KCN}$, but not rotenone, reduced calculated $\mathrm{H}_{2} \mathrm{~S}$ oxidation by at least $80 \%$ (68). These results are consistent with the mechanism of mitochondrial $\mathrm{H}_{2} \mathrm{~S}$ oxidation in which complex I is not involved (8). Taken together, these data indicate that statins increase net $\mathrm{H}_{2} \mathrm{~S}$ formation by inhibiting its mitochondrial metabolism, but have no effect on its cytosolic synthesis. To further confirm this conclusion, we isolated mitochondria from fresh liver samples, incubated them in the presence of $5 \mu \mathrm{M} \mathrm{NaHS}$, and measured sulfide concentration to calculate the rate of $\mathrm{H}_{2} \mathrm{~S}$ catabolism. Using this approach, we confirmed that $\mathrm{H}_{2} \mathrm{~S}$ was more slowly oxidized by liver mitochondria isolated from both prava- and atorvastatin-treated than from control rats (72).

\section{Mechanism of Statin-Induced Inhibition of Mitochondrial $\mathrm{H}_{2} \mathrm{~S}$ Oxidation}

The only currently known factor that may affect mitochondrial $\mathrm{H}_{2} \mathrm{~S}$ oxidation is hypoxia. However, hypoxia could not be responsible for reduced $\mathrm{H}_{2} \mathrm{~S}$ oxidation in statin-treated rats, because we measured it at a fixed level of buffer oxygenation. The next possibility which we considered was that statins reduce the activity of $S Q R$ - the first and possibly the rate-limiting enzyme in $\mathrm{H}_{2} \mathrm{~S}$ metabolism. To address this issue, we measured SQR activity in isolated liver mitochondrial membranes in the presence of saturating CoQ concentration. However, neither prava- nor atorvastatin had any effect on SQR activity (72).
Next, we asked which products of the mevalonate cascade are responsible for the effect of statins. To answer this question, we supplemented statin-treated rats with various mevalonate products or the mevalonate itself at doses which, according to previous studies, restored their concentrations to control levels. We found that only mevalonate itself, farnesol, and $\mathrm{CoQ}_{9}$ (the major $\mathrm{CoQ}$ species in the rat) normalized mitochondrial $\mathrm{H}_{2} \mathrm{~S}$ oxidation in the liver of atorvastatin or pravastatin-treated rats and in PAAT of atorvastatin-treated rats (13). In contrast, squalene and geranylgeraniol failed to normalize $\mathrm{H}_{2} \mathrm{~S}$ production. Similarly, synthetic LXR agonist, TO901317, also did not restore mitochondrial $\mathrm{H}_{2}$ S oxidation in statin-treated rats. These results suggest that statins compromise $\mathrm{H}_{2} \mathrm{~S}$ oxidation by reducing $\mathrm{CoQ}$, because both mevalonate and farnesol, but nor squalene or geranylgeraniol, are CoQ precursors (Fig. 1). In addition, we found that both prava- and atorvastatin decreased $\mathrm{CoQ}_{9}$ concentration in plasma and liver, whereas only atorvastatin did so in PAAT. Administration of exogenous $\mathrm{CoQ}_{9}$ in statin-treated rats also improved NaHS oxidation by isolated liver mitochondria (72). Finally, if isolated liver mitochondria were preincubated with synthetic $\mathrm{CoQ}_{9}$ before placing them in NaHS-containing solution, NaHS oxidation was improved in mitochondria isolated from statin-treated animals but not from control rats (72). Supplementation with $\mathrm{CoQ}_{9}$ had no effect on phenylephrine-induced contraction of PAAT - aortic rings in either control or atorvastatin-treated rats. In addition, $\mathrm{CoQ}_{9}$ did not change phenylephrine-induced contraction of PAAT + rings isolated from rats not treated with atorvastatin. However, $\mathrm{CoQ}_{9}$ supplementation increased contractility of PAAT + rings in atorvastatin-treated rats (72). In conclusion, these results indicate that statins compromise $\mathrm{H}_{2} \mathrm{~S}$ oxidation by depleting CoQ.

\section{Inhibition of Mitochondrial $\mathrm{H}_{2} \mathrm{~S}$ Oxidation by Statins: Specific Effect or Generalized Mitochondrial/Dysfunction?}

Since statins reduced mitochondrial $\mathrm{H}_{2} \mathrm{~S}$ oxidation, it is important if this effect is specific for $\mathrm{H}_{2} \mathrm{~S}$ or results from generalized impairment of mitochondrial function. In theory, statins could impair mitochondrial function by (1) decreasing CoQ and reducing the activity of CoQ-dependent respiratory complexes I, II, and/or III, (2) depleting heme A-a prosthetic group of cytochrome c oxidase, (3) reducing the amount of mitochondria in the cell.

Impairment of mitochondrial function is commonly observed in inherited CoQ deficiency (40). However, in these disorders, CoQ concentration in plasma and tissues is extremely low, usually below $10 \%$ of normal level. Decrease in CoQ after statin treatment, if observed, is much more moderate, rarely exceeding 30\%-40\%. If statins impair mitochondrial function by depleting CoQ remains highly controversial. In some studies, statin-induced mitochondrial dysfunction was observed, but this effect was usually associated with the development of side effects such as severe myopathy or hepatotoxicity, or was observed in vitro when high concentrations of statins were used. For example, Päivä et al. (48) observed that high-dose simvastatin treatment reduced combined activity of complex II and complex III (i.e., succinate: cytochrome c oxidoreductase) in skeletal muscle biopsies of patients with hypercholesterolemia. Combined activity 
of complex II and III or complex I and III is a reliable marker of CoQ availability because this activity relies on endogenous ubiquinone, in contrast to the measurement of individual activities of these complexes when exogenous CoQ is supplied at the saturating concentrations. However, in that study, (48) individual activities of complex I and IV were also reduced, and citrate synthase activity (a marker of mitochondria density in the cell) was lower in statin-treated patients, suggesting that simvastatin decreased mitochondrial density rather than impaired mitochondrial function. On the other hand, Duncan et al. (16) examined mitochondrial enzymes in two patients with symptomatic simvastatin-induced myopathy. In both of them, total activity of complex II and III was normal despite significant reduction of ubiquinone level (16). Similarly, lovastatin reduced CoQ concentration in cultured rat astrocytes by $50 \%$ but had no effect on complex I or complex II + III activities (16). Nakahara et al. found that, despite $70 \%$ reduction of CoQ in skeletal muscles of simvastatinor pravastatin-treated rabbits, combined activities of complex $\mathrm{I}+\mathrm{III}$ and II + III as well as individual activity of cytochrome c oxidase was normal (45). On the other hand, Tavintharan et al. (63) have demonstrated that simvastatin reduced CoQ in cultured HepG2 hepatocytes by $90 \%$, which was associated with the decrease in ATP synthesis by as much as $80 \%$; this effect was abolished by adding exogenous CoQ to the incubation medium. Decrease in ATP production induced by atorvastatin was also observed in cadriomyocyte mitochondria of guinea-pigs (15), and in myoblasts cultured in the presence of simvastatin, lovastatin, or fluvastatin, but not pravastatin or rosuvastatin (66). Thus, it is controversial whether statins can impair mitochondrial respiratory chain by suppressing CoQ synthesis. In addition, some studies suggest that statins may alter the amount of mitochondrial in the cell. For example, Schick et al. (53) have demonstrated that treatment with high doses of simvastatin or atorvastatin reduced mitochondrial DNA copy number in skeletal muscles of hypercholesterolemic patients. In contrast, fluvastatin increased citrate synthase activity - a marker of mitochondria densityin human HepG2 cells as well as in freshly isolated rat hepatocytes (67).

To examine whether statins specifically inhibit $\mathrm{H}_{2} \mathrm{~S}$ oxidation or have a general detrimental effect on mitochondrial function, we isolated mitochondria from the liver of statintreated rats and measured oxidation of $\mathrm{NaHS}$ as well as of organic substrate of complex II, succinate. We measured two markers of mitochondrial function: ATP production and mitochondrial membrane potential $\left(\Delta \psi_{\mathrm{m}}\right) . \Delta \psi_{\mathrm{m}}$ is potential difference across inner mitochondrial membrane, between mitochondrial matrix and mitochondrial intermembrane space (negative potential in the matrix). During electron transport through the mitochondrial respiratory chain, protons $\left(\mathrm{H}^{+}\right)$are also transferred from the matrix to the intermembrane space. The resulting $\mathrm{H}^{+}$gradient provides energy for ATP synthesis and makes mitochondria the most negatively charged organelles in the cell with a $\Delta \psi_{\mathrm{m}}$ from -150 to $-180 \mathrm{mV}$. Thus, $\Delta \psi_{\mathrm{m}}$ is a global marker of electron transport efficacy. We measured $\Delta \psi_{\mathrm{m}}$ in suspended liver mitochondria by lipophilic cationic fluorescent probe, JC-1 (13). This probe accumulates in negatively charged space of mitochondrial matrix and changes not only the intensity but also the character of fluorescence in a concentration-dependent manner. In diluted solutions, JC-1 exists as monomers, which, when ex- cited with the wavelength of $488 \mathrm{~nm}$, emit green light at $535 \mathrm{~nm}$. When JC-1 concentration increases, aggregates are formed that exhibit maximal emission within the orange range $(595 \mathrm{~nm})$. The ratio between intensity of orange-togreen fluorescence increases very sharply with increasing JC-1 concentration, which, inside mitochondria, is proportional to $\Delta \psi_{\mathrm{m}}$. To measure $\Delta \psi_{\mathrm{m}}$, we incubated suspended liver mitochondria with $1 \mu \mathrm{M} \mathrm{JC}-1$ in the presence of either succinate or $\mathrm{NaHS}$, and then measured fluorescence at both wavelengths to calculate this ratio. We found that $\Delta \psi_{\mathrm{m}}$ measured in the presence of succinate was similar in control and statin-treated rats. In contrast, $\Delta \psi_{\mathrm{m}}$ measured in the presence of NaHS was significantly lower in statin-treated in comparison to the control group (13). In addition, the highly significant correlation between $\Delta \psi_{\mathrm{m}}$ in the individual samples and the rate of NaHS oxidation was observed. Similar results were obtained when ATP synthesis by isolated mitochondria was assessed. These results indicate that statins specifically reduce $\mathrm{H}_{2} \mathrm{~S}$ oxidation while having no effect on oxidation of organic substrates. We suggest that this specificity may be accounted for by different $K_{\mathrm{m}}$ values of SQR versus complex I/complex II for CoQ; however, this hypothesis requires further research. Since under physiological conditions $\mathrm{H}_{2} \mathrm{~S}$ constitutes only a minor fraction of mitochondrial substrates, this effect of statins is unlikely to impair ATP production and cell energy status but is related only to $\mathrm{H}_{2} \mathrm{~S}$ signaling. In addition, statins did not reduce either citrate synthase activity or cytochrome $\mathrm{C}$ content in liver or PAAT (13), indicating that reduced $\mathrm{H}_{2} \mathrm{~S}$ oxidation did not result from the decrease in mitochondria density per cell.

\section{Statins, $\mathrm{H}_{2} \mathrm{~S}$, and Regulation of Insulin Sensitivity}

Enzymatic $\mathrm{H}_{2} \mathrm{~S}$ synthesis is not confined to PVAT. Indeed, $\mathrm{H}_{2} \mathrm{~S}$ is synthesized from L-cysteine also by epidydimal, perirenal, and brown adipose tissue in the rat (18). Both CSE expression and $\mathrm{H}_{2} \mathrm{~S}$ synthesis were also observed in cultured rat epidydimal adipocytes and preadipocytes, and $\mathrm{H}_{2} \mathrm{~S}$ production from cysteine was by $30 \%$ higher in mature fat cells than in preadipocytes (18).

In freshly isolated rat epidydimal adipocytes, $\mathrm{H}_{2} \mathrm{~S}$ in solution (10-1000 $\mu \mathrm{M})$ reduced basal and insulin-stimulated uptake of glucose as well as of nonmetabolizable 2-deoxyglucose in a time- and concentration-dependent manner (18). Although $\mathrm{H}_{2} \mathrm{~S}$ concentration used in that study was relatively high, the effect seems to be physiologically relevant, because it was reproduced when adipocytes were incubated in the presence of cysteine and pyridoxal 5'-phosphate to increase endogenous $\mathrm{H}_{2} \mathrm{~S}$ formation. Moreover, either PAG or $\beta$-cyano-L-alanine not only abolished cysteine + pyridoxal phosphate-induced reduction of glucose uptake, but also reduced baseline $\mathrm{H}_{2} \mathrm{~S}$ production in adipocytes and stimulated glucose uptake either in the absence or in the presence of insulin. These data indicate that $\mathrm{H}_{2} \mathrm{~S}$ produced under physiological conditions regulates glucose uptake and insulin sensitivity of adipocytes.

In primary culture of epidydimal rat adipocytes, high concentrations of glucose reduced $\mathrm{H}_{2} \mathrm{~S}$ production in a timeand concentration-dependent manner (18). Thus, negative feedback regulatory mechanism between glucose and $\mathrm{H}_{2} \mathrm{~S}$ may exist in the adipose tissue, with $\mathrm{H}_{2} \mathrm{~S}$ inhibiting glucose uptake, and glucose inhibiting the $\mathrm{CSE}-\mathrm{H}_{2} \mathrm{~S}$ pathway. 
Furthermore, CSE expression and $\mathrm{H}_{2} \mathrm{~S}$ production in adipose tissue was up-regulated in rats fed high fructose diet for 12 weeks, which is a widely used experimental model of insulin resistance (18). In addition, the significant negative correlation between $\mathrm{H}_{2} \mathrm{~S}$ production and insulin-stimulated glucose uptake in the adipose tissue was observed (18). These observations suggest that $\mathrm{CSE}-\mathrm{H}_{2} \mathrm{~S}$ system in adipose tissue may contribute to insulin resistance in the metabolic syndrome. In addition, $\mathrm{H}_{2} \mathrm{~S}$ inhibits insulin secretion by activating $\mathrm{K}_{\text {ATP }}$ channels in pancreatic $\beta$-cells (62).

Several recent studies have demonstrated that statins modulate insulin sensitivity in a drug-specific manner. Although the results are controversial, most studies indicate that hydrophilic pravastatin may improve insulin sensitivity and reduce the incidence of type 2 diabetes, whereas lipophilic statins have the opposite detrimental effects [for review, see refs. $(26,27)]$. Effect of statins on insulin sensitivity and carbohydrate metabolism is of high clinical significance. Insulin resistance is an important risk factor of cardiovascular diseases, and diabetes mellitus is one the most common causes of hyperlipidemia; thus, many statin-treated patients suffer from impaired insulin sensitivity and glucose intolerance.

Recently, we have demonstrated that pravastatin increased, whereas atorvastatin reduced insulin sensitivity measured by hyperinsulinemic euglycemic clamp in the rat (Beltowski et al., manuscript submitted for publication). In addition, pravastatin reduced fasting plasma nonesterified fatty acids and glycerol concentrations, which are the markers of adipose tissue lipolysis in vivo, whereas atorvastatin had the opposite effect. Since inhibition of lipolysis is one of the principal effects of insulin, these results indicate that pravastatin improves whereas atorvastatin impairs insulin sensitivity of the adipose tissue.

The mechanism(s) through which atorvastatin impairs insulin sensitivity of adipocytes is currently unclear. In vitro, lipophilic statins have been demonstrated to suppress differentiation of preadipocytes to more insulin sensitive mature adipocytes, decrease glycosylation of insulin receptors and their translocation to the plasma membrane, and to suppress insulin-induced trafficking of glucose transporter GLUT4 from intracellular stores to the plasma membrane (5). However, all these effects were observed at high statin concentrations, far exceeding those found in the blood of statin-treated patients. It is unclear whether atorvastatin (and possibly other lipophilic statins) increases $\mathrm{H}_{2} \mathrm{~S}$ level in other adipose tissue depots in the similar manner as it does in PVAT. If this is the case, detrimental effect of lipophilic statins on insulin sensitivity could be mediated by $\mathrm{H}_{2} \mathrm{~S}$. However, it should be noted that other adipose tissue depots contain less or no brown adipocytes, and white adipocytes contain less mitochondria than brown fat cells. Thus, the rate of mitochondrial oxidation may have a less significant effect on $\mathrm{H}_{2} \mathrm{~S}$ availability in subcutaneous or in non-PVAT visceral adipose tissue depots. The possible role of $\mathrm{H}_{2} \mathrm{~S}$ in detrimental effect of atorvastatin on insulin sensitivity is currently under research.

\section{Inhibition of $\mathrm{H}_{2} \mathrm{~S}$ Oxidation: A New Target for Pharmacotherapy?}

Currently, several possibilities are considered to augment the beneficial effects of $\mathrm{H}_{2} \mathrm{~S}$ on the cardiovascular system: (1) stimulation of $\mathrm{H}_{2} \mathrm{~S}$ synthesizing enzymes, (2) supplying more substrate (L-cysteine) for $\mathrm{H}_{2} \mathrm{~S}$ synthesis, and (3) administration of exogenous $\mathrm{H}_{2} \mathrm{~S}$ or its donors. Each of these strategies has well-known limitations. Statins are the first and are currently the only drugs shown to increase $\mathrm{H}_{2} \mathrm{~S}$ level by inhibiting its metabolism. However, other potential strategies to pharmacologically inhibit $\mathrm{H}_{2} \mathrm{~S}$ breakdown are possible, such as administration of $\mathrm{SQR}$ inhibitors (56). Inhibiting $\mathrm{H}_{2} \mathrm{~S}$ oxidation may be an interesting variant of $\mathrm{H}_{2} \mathrm{~S}$-directed pharmacotherapy. First, as exemplified by our results, statins affect $\mathrm{H}_{2} \mathrm{~S}$ metabolism in a drug- and tissue-specific manner, determined by physical properties (and possibly pharmacokinetics) of individual drugs. In addition, inhibiting $\mathrm{H}_{2} \mathrm{~S}$ oxidation is expected to stimulate $\mathrm{H}_{2} \mathrm{~S}$-mediated signaling most effectively in tissues with highest SQR activity and, in general, high oxidative metabolism such as the heart, while having less or no effect on tissues with low SQR level such as the brain (32). In contrast, $\mathrm{H}_{2} \mathrm{~S}$ or its donors are expected to increase $\mathrm{H}_{2} \mathrm{~S}$ level in a less tissue-dependent manner, and rather should be more effective in those with low SQR activity. In addition, after in vivo administration, a large fraction of $\mathrm{H}_{2} \mathrm{~S}$ released from the donors may bind to hemoglobin or other hemoproteins, limiting its intracellular availability. $\mathrm{H}_{2} \mathrm{~S}$ donors are also more likely to impair mitochondrial oxidation of organic substrates, because SQR may compete with complexes I and II for a common pool of CoQ. Indeed, in the presence of high $\mathrm{H}_{2} \mathrm{~S}$ concentration, complexes I and II may even operate in the reverse manner, that is, reducing rather than oxidizing their substrates (8). Such a possibility is unlikely if SQR is inhibited. Moreover, intracellular compartmentalization may be the advantage, that is, inhibiting $\mathrm{H}_{2} \mathrm{~S}$ oxidation will increase its concentration in mitochondria more markedly than in other intracellular compartments. That $\mathrm{H}_{2} \mathrm{~S}$ has some specific roles in mitochondria is supported by several observations. First, $\mathrm{H}_{2} \mathrm{~S}$ is synthesized in mitochondria in a 3-MST-dependent pathway, and in some tissues such as the brain, this is the main source of the gas (58). Second, $\mathrm{H}_{2} \mathrm{~S}$ increases reduced glutathione concentration in mitochondria more than in other organelles (25). Third, stimulation of mitochondrial $\mathrm{K}_{\mathrm{ATP}}$ channels may be the important mechanism of $\mathrm{H}_{2} \mathrm{~S}$-mediated inhibition of ischemia-reperfusion injury of the heart and other organs, for example, the kidney (9). Fourth, moderate inhibition of cytochrome c oxidase by intramitochondrial $\mathrm{H}_{2} \mathrm{~S}$ may also be a significant mechanism of cytoprotection (7). Finally, hypoxia increases $\mathrm{H}_{2} \mathrm{~S}$ level first of all in mitochondria, and oxygen sensing is now considered one of the principal roles of $\mathrm{H}_{2} \mathrm{~S}$ (46). Combining $\mathrm{H}_{2} \mathrm{~S}$ donors with agents suppressing its $\mathrm{H}_{2} \mathrm{~S}$ oxidation may be the other therapeutic option. Such a combination could allow potentiating the $\mathrm{H}_{2} \mathrm{~S}$ elevating effect of each individual component in the synergistic manner and to reduce their doses and avoid undesirable side effects. It should be noted that $\mathrm{H}_{2} \mathrm{~S}$, in contrast to $\mathrm{NO}$ and $\mathrm{CO}$, is the only gasotransmitter which is enzymatically metabolized giving us this additional opportunity to control its level. However, it should be kept in mind that inhibiting $\mathrm{H}_{2} \mathrm{~S}$ oxidation is a potential hazard for tissues such as colonic mucosa where effective metabolic gas clearance is essential to avoid the toxicity of $\mathrm{H}_{2} \mathrm{~S}$ generated by the commensal bacteria.

\section{Acknowledgments}

The authors' original studies quoted in this article $(13,68)$ were supported by grant DS 476 from Medical University, 
Lublin, Poland, as well as by EU Project "The equipment of innovative laboratories doing research on new medicines used in the therapy of civilization and neoplastic diseases" within the Operational Program Development of Eastern Poland 2007-2013, Priority Axis I Modern Economy, Operations I.3 Innovation Promotion.

\section{References}

1. Ali MY, Ping CY, Mok YY, Ling L, Whiteman M, Bhatia M, and Moore PK. Regulation of vascular nitric oxide in vitro and in vivo; a new role for endogenous hydrogen sulfide? $\mathrm{Br}$ J Pharmacol 149: 625-634, 2006.

2. Al-Magableh MR and Hart JL. Mechanism of vasorelaxation and role of endogenous hydrogen sulfide production in mouse aorta. Naunyn Schmiedebergs Arch Pharmacol 383: 403413, 2011.

3. Bearden SE, Beard RS, and Pfau JC. Extracellular transsulfuration generates hydrogen sulfide from homocysteine and protects endothelium from redox stress. Am J Physiol Heart Circ Physiol 299: H1568-H1576, 2010.

4. Bełtowski J, Jamroz-Wiśniewska A, and Tokarzewska D. Hydrogen sulfide and its modulation in arterial hypertension and atherosclerosis. Cardiovasc Hematol Agents Med Chem 8: 173-186, 2010.

5. Bełtowski J, Wójcicka G, and Jamroz-Wiśniewska A. Adverse effects of statins-mechanisms and consequences. Curr Drug Saf 4: 209-228, 2009.

6. Blum A and Shamburek R. The pleiotropic effects of statins on endothelial function, vascular inflammation, immunomodulation and thrombogenesis. Atherosclerosis 203: 325330, 2009.

7. Bos EM, Leuvenink HG, Snijder PM, Kloosterhuis NJ, Hillebrands JL, Leemans JC, Florquin S, and van Goor H. Hydrogen sulfide-induced hypometabolism prevents renal ischemia/reperfusion injury. J Am Soc Nephrol 20: 1901-1905, 2009.

8. Bouillaud F and Blachier F. Mitochondria and sulfide: a very old story of poisoning, feeding, and signaling? Antioxid Redox Signal 15: 379-391, 2011.

9. Calvert JW, Coetzee WA, and Lefer DJ. Novel insights into hydrogen sulfide-mediated cytoprotection. Antioxid Redox Signal 12: 1203-1217, 2010.

10. Cheang WS, Wong WT, Shen B, Lau CW, Tian XY, Tsang SY, Yao X, Chen ZY, and Huang Y. 4-aminopyridinesensitive $\mathrm{K}^{+}$channels contributes to NaHS-induced membrane hyperpolarization and relaxation in the rat coronary artery. Vascul Pharmacol 53: 94-98, 2010.

11. Cheng Y, Ndisang JF, Tang G, Cao K, and Wang R. Hydrogen sulfide-induced relaxation of resistance mesenteric artery beds of rats. Am J Physiol Heart Circ Physio 287: H2316-H2323, 2004.

12. Chiku T, Padovani D, Zhu W, Singh S, Vitvitsky V, and Banerjee $\mathrm{R}$. $\mathrm{H}_{2} \mathrm{~S}$ biogenesis by human cystathionine gammalyase leads to the novel sulfur metabolites lanthionine and homolanthionine and is responsive to the grade of hyperhomocysteinemia. J Biol Chem 284: 11601-11612, 2009.

13. Chylińska B. Effect of pravastatin and atorvastatin on synthesis and metabolism of endogenous hydrogen sulfide in the vascular wall. Ph.D. Dissertation, Medical University, Lublin, 2011.

14. d'Emmanuele di Villa Bianca R, Sorrentino R, Coletta C, Mitidieri E, Rossi A, Vellecco V, Pinto A, Cirino G, and Sorrentino R. Hydrogen sulfide-induced dual vascular effect involves arachidonic acid cascade in rat mesenteric arterial bed. J Pharmacol Exp Ther 337: 59-64, 2011.

15. Diebold BA, Bhagavan NV, and Guillory RJ. Influences of lovastatin administration on the respiratory burst of leukocytes and the phosphorylation potential of mitochondria in guinea pigs. Biochim Biophys Acta 1200: 100-108, 1994.

16. Duncan AJ, Hargreaves IP, Damian MS, Land JM, and Heales SJ. Decreased ubiquinone availability and impaired mitochondrial cytochrome oxidase activity associated with statin treatment. Toxicol Mech Methods 19: 44-50, 2009.

17. Fang L, Zhao J, Chen Y, Ma T, Xu G, Tang C, Liu X, and Geng B. Hydrogen sulfide derived from periadventitial adipose tissue is a vasodilator. J Hypertens 27: 2174-2185, 2009.

18. Feng X, Chen Y, Zhao J, Tang C, Jiang Z, and Geng B. Hydrogen sulfide from adipose tissue is a novel insulin resistance regulator. Biochem Biophys Res Commun 380: 153159, 2009.

19. Hamadmad SN and Hohl RJ. Lovastatin suppresses erythropoietin receptor surface expression through dual inhibition of glycosylation and geranylgeranylation. Biochem Pharmacol 74: 590-600, 2007.

20. Hildebrandt TM and Grieshaber MK. Three enzymatic activities catalyze the oxidation of sulfide to thiosulfate in mammalian and invertebrate mitochondria. FEBS $J$ 275: 3352-3361, 2008.

21. Ishii I, Akahoshi N, Yamada H, Nakano S, Izumi T, and Suematsu M. Cystathionine $\gamma$-lyase-deficient mice require dietary cysteine to protect against acute lethal myopathy and oxidative injury. J Biol Chem 285: 26358-26368, 2010.

22. Istvan ES and Deisenhofer J. Structural mechanism for statin inhibition of HMG-CoA reductase. Science 292: 1160-1164, 2001.

23. Jackson-Weaver O, Paredes DA, Bosc LV, Walker BR, and Kanagy NL. Intermittent hypoxia in rats increases myogenic tone through loss of hydrogen sulfide activation of largeconductance $\mathrm{Ca}^{2+}$-activated potassium channels. Circ Res 108: 1439-1447, 2011.

24. Jiang B, Tang G, Cao K, Wu L, and Wang R. Molecular mechanism for $\mathrm{H}_{2} \mathrm{~S}$-induced activation of $\mathrm{K}_{\mathrm{ATP}}$ channels. Antioxid Redox Signal 12: 1167-1178, 2010.

25. Kimura Y, Goto Y, and Kimura H. Hydrogen sulfide increases glutathione production and suppresses oxidative stress in mitochondria. Antioxid Redox Signal 12: 1-13, 2010.

26. Koh KK, Sakuma I, and Quon MJ. Differential metabolic effects of distinct statins. Atherosclerosis 215: 1-8, 2010,

27. Kostapanos MS, Liamis GL, Milionis HJ, and Elisaf MS. Do statins beneficially or adversely affect glucose homeostasis? Curr Vasc Pharmacol 8: 612-631, 2010.

28. Krause BR and Newton RS Lipid-lowering activity of atorvastatin and lovastatin in rodent species: triglyceridelowering in rats correlates with efficacy in LDL animal models. Atherosclerosis 117: 237-244, 1995.

29. Kromer A and Moosmann B. Statin-induced liver injury involves cross-talk between cholesterol and selenoprotein biosynthetic pathways. Mol Pharmacol 75: 1421-1429, 2009.

30. Laggner H, Hermann M, Esterbauer H, Muellner MK, Exner M, Gmeiner BM, and Kapiotis S. The novel gaseous vasorelaxant hydrogen sulfide inhibits angiotensin-converting enzyme activity of endothelial cells. J Hypertens 25: 21002104, 2007.

31. Laggner H, Muellner MK, Schreier S, Sturm B, Hermann M, Exner M, Gmeiner BM, and Kapiotis S. Hydrogen sulfide: a novel physiological inhibitor of LDL atherogenic modification by HOCl. Free Radic Res 41: 741-747, 2007. 
32. Lagoutte E, Mimoun S, Andriamihaja M, Chaumontet C, Blachier F, and Bouillaud F. Oxidation of hydrogen sulfide remains a priority in mammalian cells and causes reverse electron transfer in colonocytes. Biochim Biophys Acta 1797: 1500-1511, 2010.

33. Lenaz G and Genova ML. Structure and organization of mitochondrial respiratory complexes: a new understanding of an old subject. Antioxid Redox Signal 12: 961-1008, 2010.

34. Levitt MD, Abdel-Rehim MS, and Furne J. Free and acidlabile hydrogen sulfide concentrations in mouse tissues: anomalously high free hydrogen sulfide in aortic tissue. Antioxid Redox Signal 15: 373-378, 2011.

35. Li W, Tang C, Jin H, and Du J. Regulatory effects of sulfur dioxide on the development of atherosclerotic lesions and vascular hydrogen sulfide in atherosclerotic rats. Atherosclerosis 215: 323-330, 2011.

36. Li L, Whiteman M, Guan YY, Neo KL, Cheng Y, Lee SW, Zhao Y, Baskar R, Tan CH, and Moore PK. Characterization of a novel, water-soluble hydrogen sulfide-releasing molecule (GYY4137): new insights into the biology of hydrogen sulfide. Circulation 117: 2351-2360, 2008.

37. Liu $\mathrm{YH}$ and Bian JS. Bicarbonate-dependent effect of hydrogen sulfide on vascular contractility in rat aortic rings. Am J Physiol Cell Physiol 299: C866-C872, 2010.

38. Löhn M, Dubrovska G, Lauterbach B, Luft FC, Gollasch M, and Sharma AM. Periadventitial fat releases a vascular relaxing factor. FASEB J 16: 1057-1063, 2002.

39. Lu M, Liu YH, Goh HS, Wang JJ, Yong QC, Wang R, and Bian JS. Hydrogen sulfide inhibits plasma renin activity. J Am Soc Nephrol 21: 993-1002, 2010.

40. Mancuso M, Orsucci D, Volpi L, Calsolaro V, and Siciliano G. Coenzyme Q10 in neuromuscular and neurodegenerative disorders. Curr Drug Targets 11: 111-121, 2010.

41. Meng QH, Yang G, Yang W, Jiang B, Wu L, and Wang R. Protective effect of hydrogen sulfide on balloon injuryinduced neointima hyperplasia in rat carotid arteries. Am J Pathol 170: 1406-1414, 2007.

42. Moosmann B and Behl C. Selenoproteins, cholesterollowering drugs, and the consequences: revisiting of the mevalonate pathway. Trends Cardiovasc Med 14: 273-281, 2004.

43. Muellner MK, Schreier SM, Laggner H, Hermann M, Esterbauer H, Exner M, Gmeiner BM, and Kapiotis S. Hydrogen sulfide destroys lipid hydroperoxides in oxidized LDL. Biochem J 420: 277-281, 2009.

44. Muzaffar S; Shukla N, Bond M, Newby AC, Angelini GD, Sparatore A, Del Soldato P, and Jeremy JY. Exogenous hydrogen sulfide inhibits superoxide formation, NOX-1 expression and Rac1 activity in human vascular smooth muscle cells. J Vasc Res 45: 521-528, 2008.

45. Nakahara K, Kuriyama M, Sonoda Y, Yoshidome H, Nakagawa H, Fujiyama J, Higuchi I, and Osame M. Myopathy induced by HMG-CoA reductase inhibitors in rabbits: a pathological, electrophysiological, and biochemical study. Toxicol Appl Pharmacol 152: 99-106, 1998.

46. Olson KR and Whitfield NL. Hydrogen sulfide and oxygen sensing in the cardiovascular system. Antioxid Redox Signal 12: 1219-1234, 2010.

47. Olson KR, Whitfield NL, Bearden SE, St Leger J, Nilson E, Gao Y, and Madden JA. Hypoxic pulmonary vasodilation: a paradigm shift with a hydrogen sulfide mechanism. Am J Physiol Regul Integr Comp Physiol 298: R51-R60, 2010.

48. Päivä H, Thelen KM, Van Coster R, Smet J, De Paepe B, Mattila KM, Laakso J, Lehtimäki T, von Bergmann K, Lütjohann D, and Laaksonen R. High-dose statins and skeletal muscle metabolism in humans: a randomized, controlled trial. Clin Pharmacol Ther 78: 60-68, 2005.

49. Pan LL, Liu XH, Gong QH, Wu D, and Zhu YZ. Hydrogen sulfide attenuated tumor necrosis factor- $\alpha$-induced inflammatory signaling and dysfunction in vascular endothelial cells. PLoS One 6: e19766, 2011.

50. Rajsheker S, Manka D, Blomkalns AL, Chatterjee TK, Stoll LL, and Weintraub NL. Crosstalk between perivascular adipose tissue and blood vessels. Curr Opin Pharmacol 10: 191196, 2010.

51. Ridker PM, Rifai N, Clearfield M, Downs JR, Weis SE, Miles JS, and Gotto AM. Measurement of C-reactive protein for the targeting of statin therapy in the primary prevention of acute coronary events. N Engl J Med 344: 1959-1965, 2001.

52. Sacks FM, Pfeffer MA, Moye LA, Rouleau JL, Rutherford JD, Cole TG, Brown L, Warnica JW, Arnold JM, Wun CC, Davis $\mathrm{BR}$, and Braunwald E. The effect of pravastatin on coronary events after myocardial infarction in patients with average cholesterol levels. N Engl J Med 335: 1001-1009, 1996.

53. Schick BA, Laaksonen R, Frohlich JJ, Päivä H, Lehtimäki T, Humphries KH, and Côté HC. Decreased skeletal muscle mitochondrial DNA in patients treated with high-dose simvastatin. Clin Pharmacol Ther 81: 650-653, 2007.

54. Schleifenbaum J, Köhn C, Voblova N, Dubrovska G, Zavarirskaya O, Gloe T, Crean CS, Luft FC, Huang Y, Schubert $\mathrm{R}$, and Gollasch M. Systemic peripheral artery relaxation by KCNQ channel openers and hydrogen sulfide. J Hypertens 28: 1875-1882, 2010.

55. Sever PS, Dahlöf B, Poulter NR, Wedel H, Beevers G, Caulfield M, Collins R, Kjeldsen SE, Kristinsson A, McInnes GT, Mehlsen J, Nieminen M, O'Brien E, and Ostergren J. Prevention of coronary and stroke events with atorvastatin in hypertensive patients who have average or lower-thanaverage cholesterol concentrations, in the Anglo-Scandinavian Cardiac Outcomes Trial—Lipid Lowering Arm (ASCOT-LLA): a multicentre randomised controlled trial. Lancet 361: 11491158, 2003.

56. Shahak Y, Arieli B, Padan E, and Hauska G. Sulfide quinone reductase (SQR) activity in Chlorobium. FEBS Lett 299: 127130, 1992.

57. Shibuya N, Mikami Y, Kimura Y, Nagahara N, and Kimura H. Vascular endothelium expresses 3-mercaptopyruvate sulfurtransferase and produces hydrogen sulfide. J Biochem 146: 623-626, 2009.

58. Shibuya N, Tanaka M, Yoshida M, Ogasawara Y, Togawa T, Ishii $\mathrm{K}$, and Kimura H. 3-Mercaptopyruvate sulfurtransferase produces hydrogen sulfide and bound sulfane sulfur in the brain. Antioxid Redox Signal 11: 703-714, 2009.

59. Shitara $Y$ and Sugiyama Y. Pharmacokinetic and pharmacodynamic alterations of 3-hydroxy-3-methylglutaryl coenzyme A (HMG-CoA) reductase inhibitors: drug-drug interactions and interindividual differences in transporter and metabolic enzyme functions. Pharmacol Ther 112: 71-105, 2006.

60. Siddals KW, Marshman E, Westwood M, and Gibson JM. Abrogation of insulin-like growth factor-I (IGF-I) and insulin action by mevalonic acid depletion: synergy between protein prenylation and receptor glycosylation pathways. J Biol Chem 279: 38353-38359, 2004.

61. Tang G, Wu L, Liang W, and Wang R. Direct stimulation of $\mathrm{K}_{\mathrm{ATP}}$ channels by exogenous and endogenous hydrogen sulfide in vascular smooth muscle cells. Mol Pharmacol 68: 1757-1764, 2005. 
62. Taniguchi $\mathrm{S}$ and Niki I. Significance of hydrogen sulfide production in the pancreatic $\beta$-cell. J Pharmacol Sci 116: 1-5, 2011

63. Tavintharan S, Ong CN, Jeyaseelan K, Sivakumar M, Lim $\mathrm{SC}$, and Sum CF. Reduced mitochondrial coenzyme Q10 levels in HepG2 cells treated with high-dose simvastatin: a possible role in statin-induced hepatotoxicity? Toxicol Appl Pharmacol 223: 173-179, 2007.

64. Tyagi N, Moshal KS, Sen U, Vacek TP, Kumar M, Hughes WM Jr., Kundu S, and Tyagi SC. $\mathrm{H}_{2} \mathrm{~S}$ protects against methionine-induced oxidative stress in brain endothelial cells. Antioxid Redox Signal 11: 25-33, 2009.

65. Verlohren S, Dubrovska G, Tsang SY, Essin K, Luft FC, Huang $Y$, and Gollasch M. Visceral periadventitial adipose tissue regulates arterial tone of mesenteric arteries. Hypertension 44: 271-276, 2004.

66. Wagner BK, Kitami T, Gilbert TJ, Peck D, Ramanathan A, Schreiber SL, Golub TR, and Mootha VK. Large-scale chemical dissection of mitochondrial function. Nat Biotechnol 26: 343-351, 2008.

67. Wang $W$ and Wong CW. Statins enhance peroxisome proliferator-activated receptor gamma coactivator- $1 \alpha$ activity to regulate energy metabolism. J Mol Med 88: 309-317, 2010.

68. Wang $Y$, Zhao X, Jin H, Wei H, Li W, Bu D, Tang X, Ren Y, Tang $C$, and Du J. Role of hydrogen sulfide in the development of atherosclerotic lesions in apolipoprotein E knockout mice. Arterioscler Thromb Vasc Biol 29: 173-179, 2009.

69. Warner GJ, Berry MJ, Moustafa ME, Carlson BA, Hatfield DL, and Faust JR. Inhibition of selenoprotein synthesis by selenocysteine tRNA[Ser]Sec lacking isopentenyladenosine. J Biol Chem 275: 28110-28119, 2000.

70. Webb GD, Lim LH, Oh VM, Yeo SB, Cheong YP, Ali MY, El Oakley R, Lee CN, Wong PS, Caleb MG, Salto-Tellez M, Bhatia M, Chan ES, Taylor EA, and Moore PK. Contractile and vasorelaxant effects of hydrogen sulfide and its biosynthesis in the human internal mammary artery. J Pharmacol Exp Ther 324: 876-882, 2008.

71. Whiteman M, Li L, Rose P, Tan CH, Parkinson DB, and Moore PK. The effect of hydrogen sulfide donors on lipopolysaccharide-induced formation of inflammatory mediators in macrophages. Antioxid Redox Signal 12: 1147-1154, 2010.

72. Wójcicka G, Jamroz-Wiśniewska A, Atanassova P, Chaldakov GN, Chylińska-Kula B, and Bełtowski J. Differential effects of statins on endogenous $\mathrm{H}_{2} \mathrm{~S}$ formation in perivascular adipose tissue. Pharmacol Res 63: 68-76, 2011.

73. Wu SY, Pan CS, Geng B, Zhao J, Yu F, Pang YZ, Tang CS, and Qi YF. Hydrogen sulfide ameliorates vascular calcification induced by vitamin $\mathrm{D}_{3}$ plus nicotine in rats. Acta Pharmacol Sin 27: 299-306, 2006.

74. Yamashita S, Tsubakio-Yamamoto K, Ohama T, NakagawaToyama Y, and Nishida M. Molecular mechanisms of HDLcholesterol elevation by statins and its effects on HDL functions. J Atheroscler Thromb 17: 436-451, 2010.

75. Yan SK, Chang T, Wang H, Wu L, Wang R, and Meng QH. Effects of hydrogen sulfide on homocysteine-induced oxidative stress in vascular smooth muscle cells. Biochem Biophys Res Commun 351: 485-491, 2006.

76. Yang G Wu L, Jiang B, Yang W, Qi J, Cao K, Meng Q, Mustafa AK, Mu W, Zhang S, Snyder SH, and Wang R. $\mathrm{H}_{2} \mathrm{~S}$ as a physiologic vasorelaxant: hypertension in mice with deletion of cystathionine gamma-lyase. Science 322: 587-590, 2008.

77. Zagli G, Patacchini R, Trevisani M, Abbate R, Cinotti S, Gensini GF, Masotti G, and Geppetti P. Hydrogen sulfide inhibits human platelet aggregation. Eur J Pharmacol 559: 6568, 2007.

78. Zhao $\mathrm{W}$ and Wang $\mathrm{R} . \mathrm{H}_{2} \mathrm{~S}$-induced vasorelaxation and underlying cellular and molecular mechanisms. Am J Physiol Heart Circ Physiol 283: H474-H480, 2002.

79. Zhao W, Zhang J, Lu Y, and Wang R. The vasorelaxant effect of $\mathrm{H}_{2} \mathrm{~S}$ as a novel endogenous gaseous $\mathrm{K}_{\mathrm{ATP}}$ channel opener. EMBO J 20: 6008-6016, 2001.

80. Zhao ZZ, Wang Z, Li GH, Wang R, Tan JM, Cao X, Suo R, and Jiang ZS. Hydrogen sulfide inhibits macrophage-derived foam cell formation. Exp Biol Med. 236: 169-176, 2011.

Address correspondence to: Prof. Jerzy Bettowski

Department of Pathophysiology Medical University ul. Jaczewskiego 8 20-090 Lublin

Poland

E-mail: jerzy.beltowski@umlub.pl jerzybel@hotmail.com

Date of first submission to ARS Central, October 27, 2011; date of acceptance, October 28, 2011.

\section{Abbreviations Used}

3-MST = 3-mercaptopyruvate sulfurtransferase 24,25-EC $=24(\mathrm{~S}), 25$-epoxycholesterol

$\mathrm{ADRF}=$ adipose tissue-derived relaxing factor AE-2 $=$ anion exchanger-2

$\mathrm{CAT}=$ cysteine aminotransferase

$\mathrm{CBS}=$ cystathionine $\beta$-synthase

$\mathrm{CSE}=$ cystathionine $\gamma$-lyase

$\mathrm{CoQ}=$ coenzyme $\mathrm{Q}$

$\mathrm{CYP}=$ cytochrome $\mathrm{P} 450$

eNOS $=$ endothelial nitric oxide synthase

HMG-CoA = 3-hydroxy-3-methylglutaryl coenzyme A $\mathrm{LDL}=$ low-density lipoprotein

LDL-R $=$ low-density lipoprotein receptor $\mathrm{LXR}=$ liver $\mathrm{X}$ receptor

$\mathrm{NO}=$ nitric oxide

$\mathrm{NOX}=\mathrm{NADPH}$ oxidase

$\mathrm{ONOO}^{-}=$peroxynitrite

$\mathrm{PAAT}=$ periaortic adipose tissue

PAG $=$ propargylglycine

PVAT $=$ perivascular adipose tissue

$\mathrm{PON}=$ paraoxonase

ROS $=$ reactive oxygen species

$\mathrm{SQR}=$ sulfide:quinone oxidoreductase

SREBP-2 = sterol regulatory element-binding protein-2 